\title{
AMS-dependent and independent regulation of anther transcriptome and comparison with those affected by other Arabidopsis anther genes
}

\author{
Xuan $\mathrm{Ma}^{1,2}$, Baomin Feng ${ }^{1,4}$ and Hong $\mathrm{Ma}^{3^{*}}$
}

\begin{abstract}
Background: In flowering plants, the development of male reproductive organs is controlled precisely to achieve successful fertilization and reproduction. Despite the increasing knowledge of genes that contribute to anther development, the regulatory mechanisms controlling this process are still unclear.

Results: In this study, we analyzed the transcriptome profiles of early anthers of sterile mutants aborted microspores (ams) and found that 1,368 genes were differentially expressed in ams compared to wild type anthers, affecting metabolism, transportation, ubiquitination and stress response. Moreover, the lack of significant enrichment of potential AMS binding sites (E-box) in the promoters of differentially expressed genes suggests both direct and indirect regulation for AMS-dependent regulation of anther transcriptome involving other transcription factors. Combining ams transcriptome profiles with those of two other sterile mutants, spl/nzz and ems 1/exs, expression of 3,058 genes were altered in at least one mutant. Our investigation of expression patterns of major transcription factor families, such as $6 H L H, M Y B$ and MADS, suggested that some closely related homologs of known anther developmental genes might also have similar functions. Additionally, comparison of expression levels of genes in different organs suggested that anther-preferential genes could play important roles in anther development.

Conclusion: Analysis of ams anther transcriptome and its comparison with those of spl/nzz and ems 1/exs anthers uncovered overlapping and distinct sets of regulated genes, including those encoding transcription factors and other proteins. These results support an expanded regulatory network for early anther development, providing a series of hypotheses for future experimentation.
\end{abstract}

\section{Background}

In flowering plants, male reproductive organs are called stamens, each of which consists of a filament and an anther [1]. Cells in the anther undergo meiosis to produce microspores, which further develop into mature pollen grains [2]. Therefore, anther development is critical to achieve pollen formation and subsequent success of fertilization [3-6]. According to morphological features, anther development can be grouped into two phases and then be further divided into 14 anther stages $[5,7,8]$. At the beginning of phase 1 (anther stages 1 to 8 ), the stamen primordium has 3 layers, L1-L3 from surface

\footnotetext{
* Correspondence: hongma@fudan.edu.cn

${ }^{3}$ State Key Laboratory of Genetic Engineering, Institute of Plant Biology, Center for Evolutionary Biology, School of Life Sciences, Institutes of Biomedical Sciences, Fudan University, Shanghai 200433, China Full list of author information is available at the end of the article
}

to interior. The L1 cells later become the epidermis and the L3 cells give rise to the vascular and connective tissues. Some of the L2 cells develop into archesporial cells which then divide into parietal cells and primary sporogenous cells. Additional cell division and differentiation in the L2-lineage establish a characteristic four-lobed structure at anther stage 5. Each lobe consists of central pollen mother cells surrounded by outer endothecium, middle layer and inner tapetum. Pollen mother cells undergo meiosis at stage 5-6, producing tetrads at stage 7. Dissolution of the tetrad callose wall releases microspores at stage 8 . In phase 2 , the microspores undergo mitosis and develop into mature pollen grains during stages 9-12. Meanwhile, pollen wall materials are deposited from both the microspores and the tapetum layer. After the degeneration of tapetum, the mature pollen is released and is able to start pollination.

\section{C) Biomed Central}


Previous studies indicated that early anther development depends on transcriptional regulation and cell-cell communication [5,7-9]. The SPOROCYTELESS (SPL)/ NOZZLE (NZZ) gene is one of the earliest genes that regulate anther cell fate determination [10,11]. SPL/NZZ is activated by $A G$, a $C$ function gene in the $A B C$ model [12-14]. $S P L / N Z Z$ is expressed as early as anther stage 2-5 and a mutation in $S P L / N Z Z$ leads to the failure of differentiation of parietal and sporogenous cells, and consequentially blocks the formation of anther wall and microsporocytes $[15,16]$.

EXCESS MALE SPOROCYTES1 (EMS1) and TAPETUM DETERMINANT1 (TPD1) are also essential for male fertility with a later expression peak at stage 5 [17]. EMS1 is a leucine-rich repeat receptor-like protein kinase (LRR-RLKs) and TPD1 is likely its ligand $[15,18,19]$. In both ems 1 and tpd 1 mutants, anthers produce more microsporocytes at the expense of the tapetum, indicating that communication between adjacent cell layers determines the cell fate of archesporial cell progenies in order to form normal anther wall [17]. Besides EMS1 and $T P D 1$, other cell-cell communication-related genes are also involved in anther development, such as SOMATIC EMBRYOGENESIS RECEPTORLIKE KINASES $1 / 2$ (SERK1/2), and RECEPTORLIKE PROTEIN KINASE2 (RPK2) [20,21].

Upon the formation of the anther lobes, DYSFUNCTIONAL TAPETUM1 (DYT1) and AMS, encoding two bHLH transcription factors, are required for tapetal functions at subsequent stages [22,23]. In $d y t 1$, tapetum cells harbor enlarged vacuoles and reduced cytoplasm. The dyt 1 meiocytes have comparatively thin callose walls, cannot complete cytokinesis and finally collapse. RNA in situ hybridization experiments showed that DYT1 reaches its peak expression at anther stage 5 to 6 [22]. $A M S$ functions near the time of meiosis, slightly later than that of DYT1. In the ams mutant, the microsporocytes can complete meiosis but the tapetum cells prematurely collapse and microspores are degraded before the first pollen mitosis [23]. Beside these regulators, a large number of other genes are also expressed in the anther, and mutations in some of them lead to male sterility by affecting early anther cell formation, tapetum formation, meiosis or pollen maturation [5,7,16,24-28].

However, due to the functional redundancy of members of many gene families, the subtleties of the phenotypes of single-gene mutants, and possible early phenotypes that obscure anther function, forward genetics has limitations in uncovering anther gene functions [29]. Expression profiling has become increasingly informative and might circumvent the limitation of forward genetics. In recent years, global gene expression profiling by microarray has been used to detect floral gene expression and obtain clues for understanding reproductive development. However, most studies to investigate stamen expression profiles have been conducted by analyzing transcripts from the whole inflorescences of male sterile mutants [30-35], rather than the anther itself [32]. Little transcriptomic information about specific organs is currently available, especially for Arabidopsis whose male reproductive organs are quite tiny $[32,33,36]$. Thus the detection of anther-specific or preferential genes in mixed floral tissues might be hampered by the moderate detection sensitivity of microarray technology. As mentioned above, SPL, EMS1 and AMS have important functions at different stages of anther development, although they have temporal overlap of expression [10,17,22,23]. Therefore, analysis of their shared and distinct effects on the anther transcriptome can shed some light on gene regulatory networks [37-39].

To obtain more information on transcriptomes near the stage of meiosis, we collected anthers at stage 4 to 7 from ams mutants and wild-type Arabidopsis, even though it is time consuming and technically difficult to dissect developing anthers, because we wanted to identify the genes affected by the ams mutation that might be too diluted to detect using RNAs from whole-inflorescences. The ams transcriptome data and comparison with previous data from $s p l$ and ems1 anthers [32] provide detailed information on early anther development. Additionally, with known information of other floral organs in Arabidopsis, we identified genes that function during early anther stage around meiosis. We found that many transcription factor genes were preferentially expressed during early anther development, such as $b H L H, M Y B$, and $M A D S$. Closely related homologs were hypothesized to have either redundant or divergent functions according to phylogenic studies [40-42]. Moreover, further investigation of organ-specific transcriptome revealed the importance of both anther-specific and non-specific transcription factors in early anther development. We propose an expanded gene regulatory network that contributes to the precise regulation of temporal and spatial events during early anther development.

\section{Results and discussion}

\section{Identification of genes regulated by AMS}

To characterize genes involved in tapetum development and function near the time of meiosis, we isolated total RNA of stage 4-7 anthers from wild-type and the ams mutant plants for Affymatrix ATH1 microarray analysis. We included three biological replicates for each genotype and the results are highly reproducible (with correlation coefficients higher than 0.96, Supplemental figure 1 in Additional file 1). We identified 1,368 genes that were differentially expressed in ams compared with wild-type anthers with at least 2 -fold differences $(P<0.05)$ 
(Additional file 2) [32,43]. The scatter-plot of the 1,368 genes shows that they include genes expressed at different levels (Figure $1 \mathrm{~A}, \mathrm{~B}, 1^{\text {st }}$ sheet in Additional file 2); furthermore, genes with higher expression in ams than wild-type tend to have low wild type expression, whereas those with lower than normal expression in ams tend to be expressed at higher levels (Figure 1B).

Recently, Xu et al. reported totally 549 genes that are differentially expressed in ams floral buds compared with wild-type buds, at four different stages using two color arrays, including 134 genes that were differentially expressed near the time of meiosis (Additional file 2) [35]. Among the 1,368 genes identified in our study, 90 were also identified by $\mathrm{Xu}$ et al. in floral buds (Figure 1C). Because $A M S$ is expressed from near anther stage 6 (meiosis) through the formation of microspores, our samples from early stage anthers allowed an examination of the early AMS function in regulating transcriptome and sensitive detection of expression shifts without dilution by other floral tissues, resulting in the identification of additional 1,278 genes (478 down- and 800 upregulated in the ams anthers) with differential expression between wild-type and ams anthers (Figure 1C).

Nevertheless, our results and the previous study did both detect 90 genes that are significantly affected by the ams mutation (Additional file 2; Figure 1C) [35].

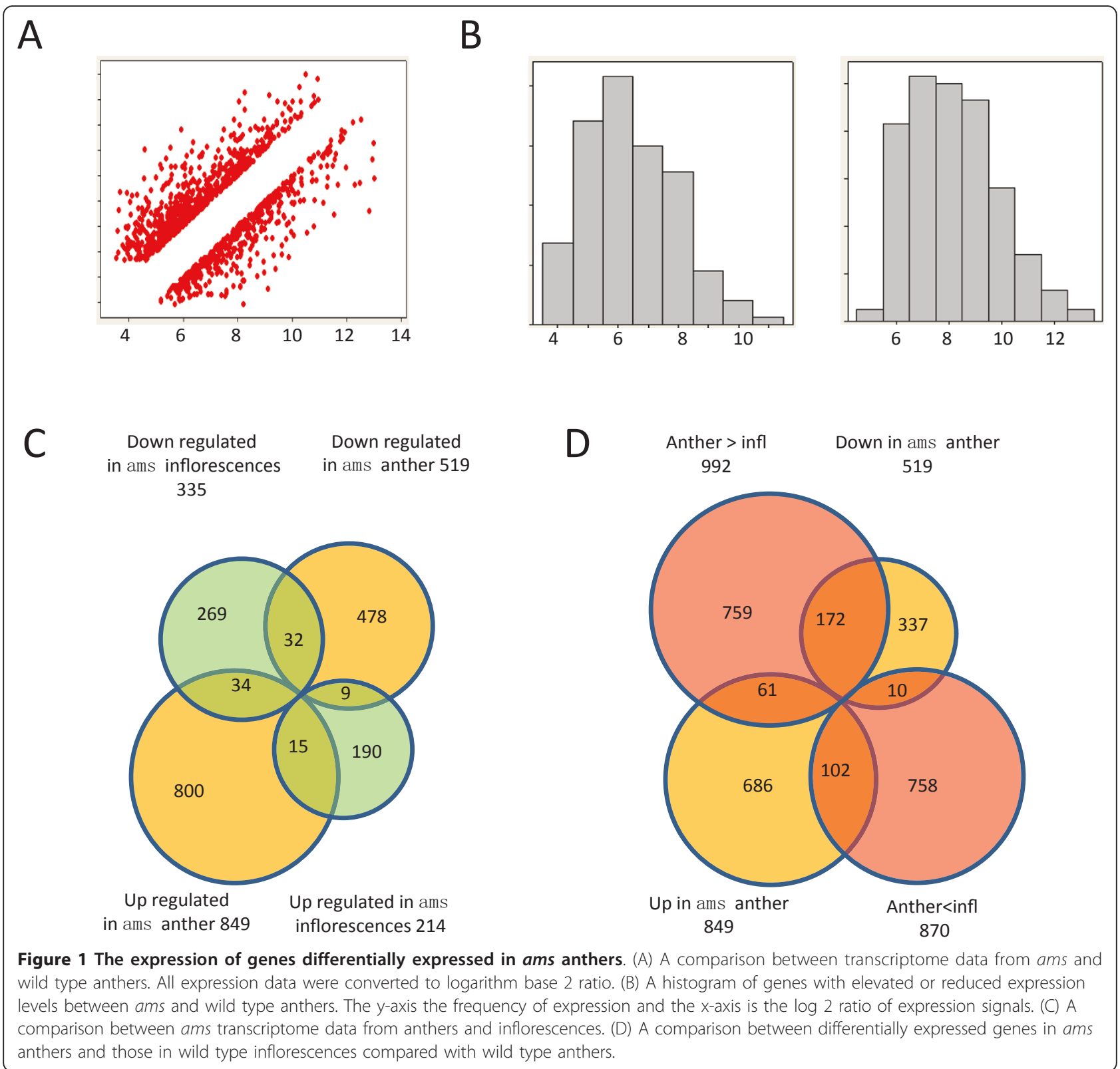


Some of these genes show the same direction in expression shifts between the two studies; however, others had the opposite directions (Figure 1C). Specifically, 34 genes with higher expression in the ams anther than the wild-type anther had reduced expression levels in the ams inflorescence compared with the wild-type inflorescence (Additional file 2); 9 genes showed the opposite trend. These differences might be due to the difference of sampling anther vs. flower bud that included later stages, although other possibilities cannot be ruled out. We observed more similar expression pattern between our anther transcriptome and the published flower bud transcriptome at meiosis stage (Additional file 2). 172 out of the 519 genes down-regulated in ams were expressed significantly higher in the wild type anther than the inflorescence, while 102 of the 849 up-regulated genes showed this pattern $(\mathrm{P}$-value $<0.05$, Figure $1 \mathrm{D}$, Additional file 2), suggesting that preferential anther expression contributed to the difference between the two studies. It is also possible that the loss of $A M S$ function might affect other aspects of flower development than anther development, although not revealed by phenotypic changes.

The GO categorization analysis of our anther transcriptome results showed that categories of enzymes, transporters, structural and other molecular proteins were over-represented in the genes with reduced expression, and hydrolases in those with elevated expression levels in ams compared with wild-type (Figure 2A-C, Additional file 3). To further investigate the putative functions of genes with different expression patterns in the ams anther from inflorescence, we then applied GO categorization to all the newly found differentially expressed genes in the ams anther. We found that some categories were enriched in those with reduced expression levels in the ams anther, such as structural molecules, transporters, oxidoreductases (supplemental figure 2 \& 3 in Additional file 1). These categories are associated with metabolic activities that are very dynamic in tapetum, suggesting a positive role of AMS in regulating metabolic functions in the tapetum. Meanwhile, genes with ion binding, glycosyl-transferase and hydrolase activities were enriched among the genes activated in ams.

As a putative bHLH transcription factor, AMS has the ability to bind to the canonical bHLH binding site (E-box: CANNTG) in vitro and in vivo [35]. In order to find candidate AMS target genes, we searched E-box elements within $1 \mathrm{~kb}$ upstream sequences of genes with statistically significant differential expression between ams and wildtype anthers (Figure 3A \&3B). We did not find statistically significant interaction between the number of E-boxes in the putative promoter regions and the fold change in gene expression (compared with randomly selected genes on the chip). It is possible that active AMS binding sites are located not just in the 1-kb regions being analyzed, but also in regions further upstream or even downstream of the coding region. It is also possible that a number of the genes affected in the ams anthers are indirectly regulated by AMS, hence not containing AMS-binding sites in their promoters.

\section{AMS affects genes with putative functions in phosphorylation, exocytosis, stress-response and ubiquitin-proteasome pathways during male reproduction} Both somatic and reproductive cells were evidently affected in the ams mutant anther, morphologically and transcriptomically [23,35]. Specifically, the ams inflorescence showed reduced expression of genes predicted to be involved in metabolism, such as lipid synthesis-related genes [35]. Our anther transcriptome data provided spatially more specific information for the expression patterns of metabolism-related genes (Supplemental figure 4 in Additional file 1) and showed that the expression levels of genes involved in cell wall formation, lipid synthesis and secondary metabolism were obviously altered in the ams anther, consistent with morphological defects.

Interestingly, 32 genes located on chloroplast DNA were reduced in expression in the ams anthers whereas starch and sucrose related genes were increased (Additional file 4 , supplemental figure 4 in Additional file 1). In addition, more metabolism-related genes were found with shifted expression, especially glycosyl-transferase $(P<0.01$, supplemental figure 5 in Additional file 1,). Besides, the expression levels of genes with putative regulatory functions were also changed, such as kinases and transcription factors (supplemental figure 6-8 in Additional file 1). Interestingly, most of the genes encoding kinases with expression shifts were activated in the ams mutant, suggesting a putative negative regulatory role of AMS (supplemental figure 4 in Additional file 1).

In addition, we found that genes likely involved in vesicular transport were up-regulated in ams, including genes encoding two SNARE proteins and others related to this process: 3 syntaxins, 3 myosin heavy chains and 2 clathrin proteins (Additional file 4, supplemental figure 9 in Additional file 1). Intracellular trafficking machinery such as SNARE complex is important in animal and plant development $[44,45]$; for example, one SNARE protein, SEC22, is preferentially expressed in the flower and essential for gametophyte development [46]. Other vesicular transport genes, such as AtVAM3 encoding a syntaxin-related protein, were shown to function in vacuolar assembly in Arabidopsis [47]. It is possible that the higher than normal expression of genes for vesicular transport contributes to the abnormally vacuolated tapetal cells observed in the ams anther [23]. 

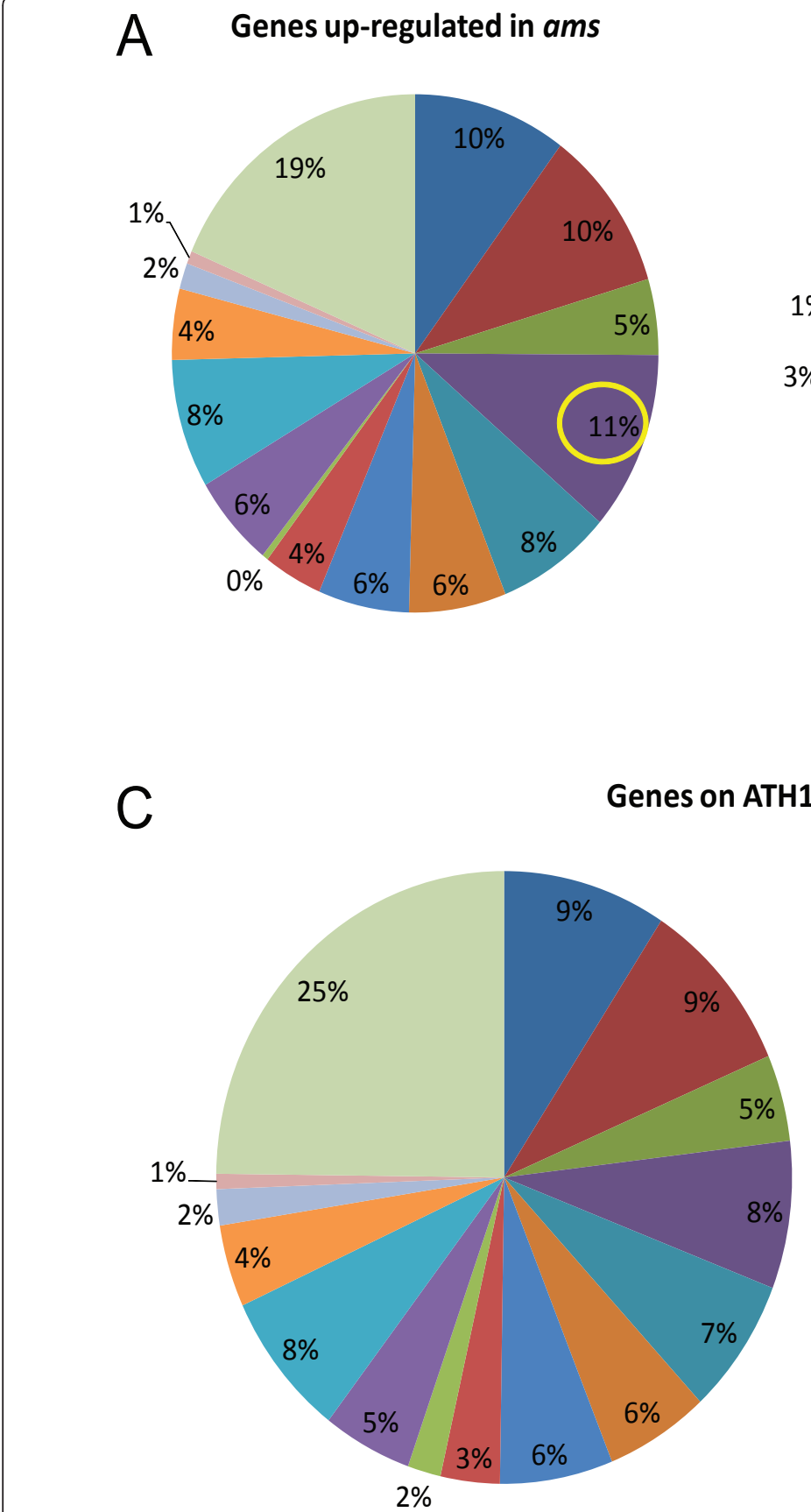

B Gene down-regulated in ams

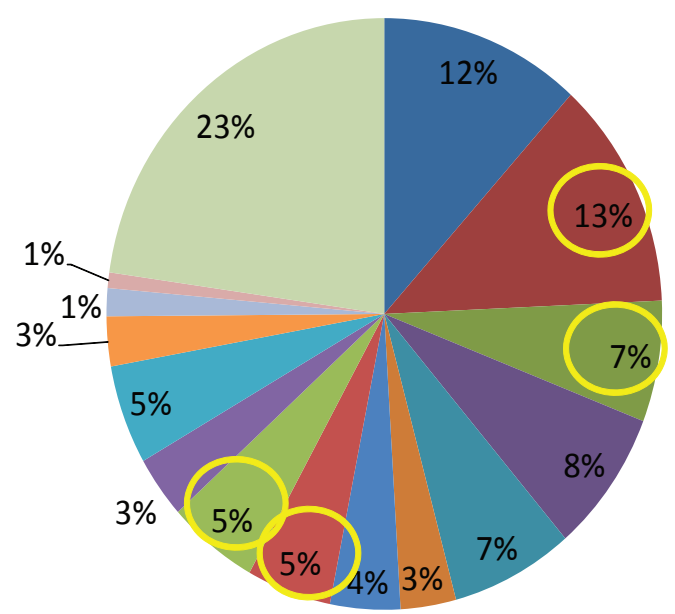

Figure 2 A pie graph of GO categorization of genes differentially expressed in the ams mutant. (A-B) GO categorization of genes up- and down-regulated in ams, with enriched categories circled compared with all genes on ATH1. (C) GO categorization of all genes on the ATH1 chip.

We also found that the expression levels of stressresponsive genes were changed in ams (Additional file 4, Supplemental figure 10 in Additional file 1), especially the increased expression of 10 disease resistance genes and two genes encoding respiratory burst oxidases. These findings are consistent with recent studies showing that multiple abiotic stresses can lead to male sterility, such as extreme temperatures and drought [48-50].
In addition, some stress-inducible and/or hormonerelated genes were also found with expression alteration, including $R D 22$, an $\mathrm{ABA}$-inducible gene responsive to dehydration; VSP1, a JA-inducible gene; EPS1, a gene possibly acting upstream of SA; CCR1, a cold inducible gene; four disease resistance genes encoding TIR-NBSLRR class proteins; and three heat-shock genes, suggesting complex interactions between internal and external 

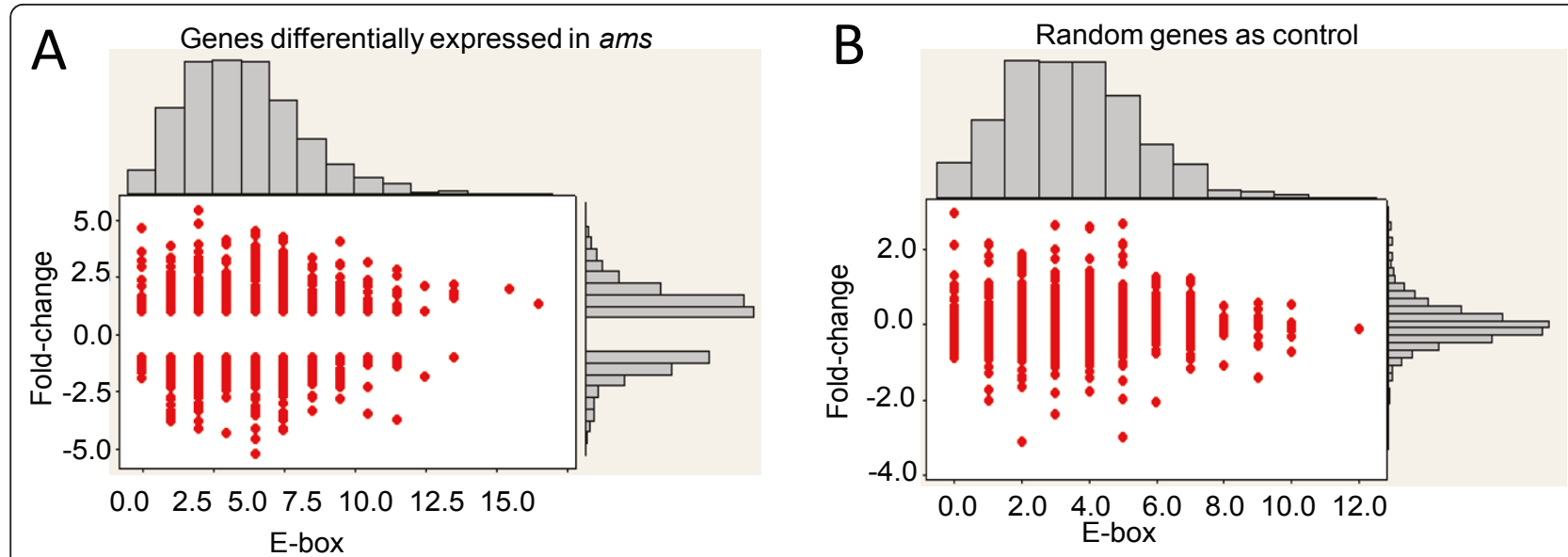

Figure 3 Marginal plot of fold changes of expression and number of E-box. (A) Genes differentially expressed in the ams anther compared with wild-type anther were selected (more than two fold changes with $P<0.05$ ). The logarithm 2 ratio of fold-changes and the number of AMS binding sites (E-box) within $1 \mathrm{~kb}$ putative promoter sequence upstream of the start codon were plotted. (B) Randomly selected genes were plotted as control.

signals regulating anther development and/or functions [51].

Another regulatory pathway activated in ams is the ubiquitin-proteasome pathway (Additional file 4), with increased expression of genes encoding subunits of the E3 ubiquitin ligases (Supplemental figure 11 in Additional file 1) [52]. Previous studies demonstrated essential roles of the ubiquitin-proteasome pathway in embryogenesis, hormone signaling, light response, floral development, self-incompatibility, and senescence $[48,52,53]$. Our results suggested that this pathway may also be regulated by AMS. It is possible that AMS directly regulates the expression of some genes in the ubiquitin-proteasome pathway; alternatively, AMS could influence the expression of such genes indirectly either via AMS-target genes or possibly through the accumulation of damaged proteins which then induce the ubiquitin-proteasome pathway [54]. Further experiments are needed to test these hypotheses.

\section{Anther-specific or preferential genes were over- represented among genes differentially expressed in the ams mutant}

Differential expression patterns in vegetative and floral organs can provide clues about gene functions [43]. To find out the relationship between the gene expression shifts in the ams mutant and their expression preferences in different organs, we compared our data from wild-type anther with previous microarray data from roots, stems, leaves, seedlings, siliques and inflorescences. The same RNA extraction method and ATH1 platform were applied in both studies so the datasets should be comparable [43]. We defined as anther-specific (A-S) using these criteria: 1) the expression in anther is significantly higher than in any other tissue (with FDR $<0.05$ ); 2) the expression is present in anther but not in any other tissues according to two alternative methods (see materials and methods for details and explanations) [43]. Using the presence call of the MAS5 algorithm identified 124 A-S genes, 76 of which had at least two fold difference; using expression level of 50 as threshold identified $172 \mathrm{~A}-\mathrm{S}$ genes, 146 of which had at least two fold difference (those with two fold differences are marked with "*:" in the second column in Additional file 5). Because both methods for calling "presence" have limitations, only the 43 genes detected by both methods were discussed as A$\mathrm{S}$ gene (this rule also applied to the two groups described below).

Genes were defined as anther-preferential (A-P) if the expression in the anther is: 1) significantly higher than those in any other tissue with FDR $<0.05$ (genes with more than 2 fold changes were marked with ":"* in Additional file 5 and Additional file 3) present in anther according to the MAS5 algorithm or with expression level of at least 50. Therefore, A-P genes included A-S genes. In addition, those with statistically significantly higher expression levels in anther than in non-floral organs were called reproductive preferential (R-P) genes (Additional file 5, see material and methods for detail). We performed real-time PCR for 6 of these genes and the results were consistent (supplemental figure 12 in Additional file 1). In our result, 24 genes involved in male reproductive development were detected (Table 1). Consistent with previous studies, SPL was found in the A-P group and EMS1 in R-P group, while $A M S$ as an A-S gene $[10,17]$.

Recently, other studies were conducted to identify male reproductive development-related genes. Wellmer et al. identified genes expressed in stamen indirectly by 
Table 1 Expression of genes known as anther development related genes

\begin{tabular}{|c|c|c|c|c|c|c|c|}
\hline AGI & Name & wt & $s / w$ & $e / w$ & $a / w$ & Function & References \\
\hline \multicolumn{8}{|c|}{ A-S } \\
\hline AT2G16910 & AMS & 7.7 & -3.4 & -3.5 & 1.7 & tapetum dev. & Sorensen et al., 2003 \\
\hline AT1G66170 & MMD1 & 5.5 & -1.8 & -1.8 & -0.1 & male meiosis & Alves-Ferreira et al., 2007 \\
\hline AT1G01280 & CYP703A2 & 9.8 & -6.2 & -6.2 & -0.6 & \multirow[t]{2}{*}{ pollen dev. and sporopollenin biosynthesis } & Souza et al., 2009 \\
\hline AT1G62940 & ACOS5 & 11.6 & -6.4 & -5.7 & -1.0 & & \\
\hline AT3G11980 & MS2 & 10.6 & -6.1 & -5.9 & -0.6 & & \\
\hline AT4G28395 & A7 & 9.6 & -4.1 & -3.9 & 0.5 & & Rubinelli et al., 1998 \\
\hline \multicolumn{8}{|c|}{ A-P } \\
\hline AT2G17950 & WUSCHEL 1 & 7.7 & -2.5 & 0.4 & 0.5 & floral dev. & Ming et al., 2009 \\
\hline AT4G27330 & $\mathrm{NZZ/SPL}$ & 9.3 & -3.9 & -0.5 & -0.5 & \multirow[t]{4}{*}{ early anther formation } & Ito et al., 2004 \\
\hline AT5G14070 & ROXY2 & 9.1 & -3.2 & -1.7 & -0.2 & & Xing et al., 2008 \\
\hline AT3G11440 & MYB65 & 8.9 & -2.2 & -0.5 & -0.4 & & Millar et al., 2005 \\
\hline AT5G06100 & MYB33 & 7.6 & -1.1 & 0.1 & -0.4 & & \\
\hline AT3G42960 & ATA1 & 11.9 & -7.4 & -6.7 & -1.7 & \multirow[t]{3}{*}{ tapetum function } & Lebel-Hardenack et al., 1997 \\
\hline AT3G51590 & LTP12 & 10.4 & -6.1 & -5.2 & 0.9 & & Ariizumi et al., 2002 \\
\hline AT3G28470 & MYB35 & 8.6 & -4.9 & -4.5 & 0.0 & & Zhu et al., 2008 \\
\hline AT1G69500 & CYP704B1 & 11.5 & -7.4 & -7.0 & -2.0 & \multirow[t]{4}{*}{ pollen dev. and sporopollenin biosynthesis } & Souza et al., 2009 \\
\hline AT4G34850 & LAP 5 & 11.4 & -6.3 & -5.8 & -1.6 & & Dobritsa et al., 2010 \\
\hline AT4G35420 & DRL1 & 11.9 & -5.1 & -4.6 & -1.9 & & Tang et al., 2009 \\
\hline AT5G62080 & MTG10 & 13.0 & -7.4 & -5.2 & -4.2 & & Xing et al., 2007 \\
\hline AT3G22880 & DMC1 & 10.7 & -2.2 & -0.1 & 0.0 & male meiosis & Doutriaux et al., 1998 \\
\hline AT3G15400 & ATA20 & 12.1 & -6.6 & -5.6 & 0.1 & pollen wall & Rubinelli et al., 1998 \\
\hline \multicolumn{8}{|c|}{ R-P } \\
\hline AT5G20240 & $\mathrm{Pl}$ & 11.8 & 0.4 & 0.0 & 0.2 & whorl specification & Li et al., 2008 \\
\hline AT3G17010 & B3 & 8.7 & 0.9 & 0.4 & 0.3 & early anther formation & Gomez-Mena et al., 2005 \\
\hline At5G07280 & EMS1 & 10.2 & -0.9 & -2.9 & 0.1 & & Zhao et al., 2002 \\
\hline AT1G71830 & SERK1 & 8.0 & 0.8 & 0.1 & 0.1 & & Albrecht et al., 2005 \\
\hline
\end{tabular}

"wt", wild-type; "s/w", fold change of the spl signals compared with wild-type; "e/w", of ems1; "a/w", of ams. A-S represents anther specific; A-P represents anther preferential (A-S excluded) and R-P represents reproductive preferential (A-S \& A-P excluded). All expression values are log2 ratio. "dev" means "development" (Column sequence, abbreviation and the version of annotation are used as in tables and supplemental tables below.)

comparing the inflorescence transcriptome of floral homeotic mutants lacking stamens with wild-type [30]. In another study, Honys et al. analyzed microspores/pollen from different stages and defined the male gametophytic transcriptome [33]. A comparison of our A-P genes with these two previous gene lists (defined as stamen and pollen, Additional file 6) revealed that only a small number of genes overlapped between the three male reproductive datasets (Figure 4A, Additional file 6). The differences in identified genes can be explained by the difference of samples used in different studies: our samples only included wild-type anthers at early stages (stage 4-7), whereas the pollen transcriptome data were from microspores and pollen at different stages; and stamen-specific genes was indirectly obtained by subtraction of mutant transcriptome from wild-type and genes in this list might function earlier during organ specification. The dramatic differences between different samples suggest strongly that gene activities alter dramatically between different developmental stages of male reproductive organs [33].

We analyzed the GO categorization for possible enrichment of specific categories among the groups of differentially expressed genes (Additional file 3 ) and found that, among the 266 A-P genes, the over-represented GO categories were hydrolases, proteins with other binding activities, and other enzymes. No enrichment of other enzyme activity was detected in pollen-specific or stamen-specific datasets found previously [33], suggesting a specific expression profile of early anther development.

Among genes with differential expression in ams, the percentage of A-P genes (5\%) is significantly higher than its percentage in the whole genome (1\%) (Figure 4B, Additional file 2 and Additional file 3). The stamen-specific genes were also enriched among those differentially expressed in ams (9\%) compared with whole genome data 

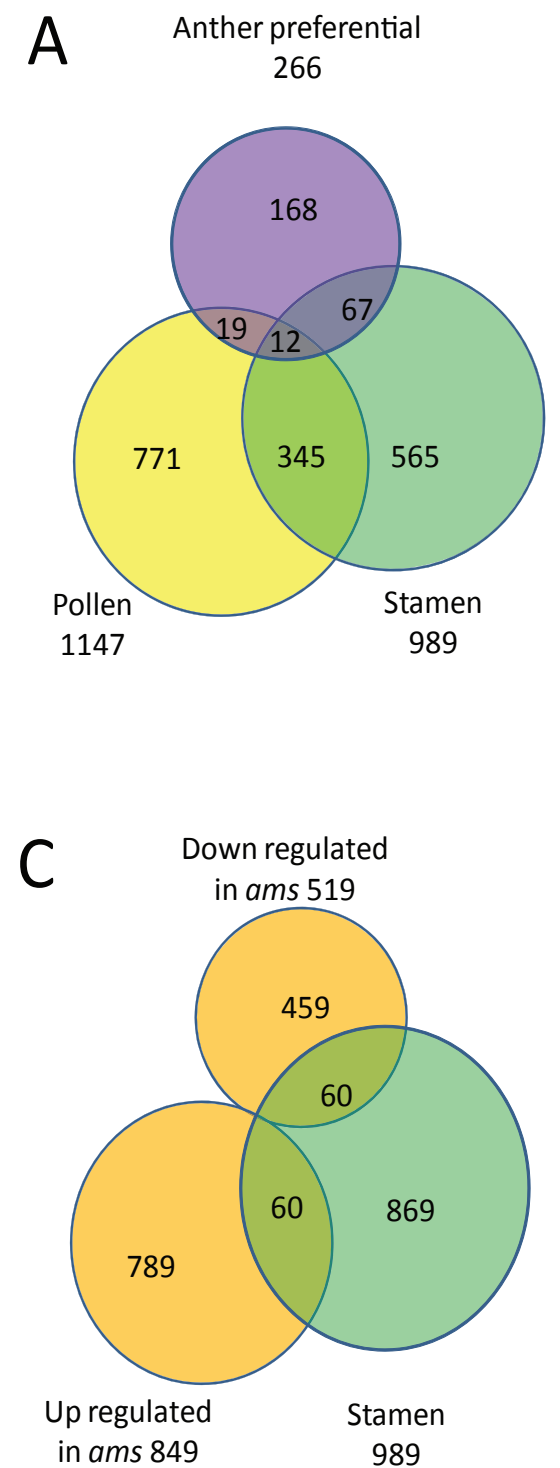
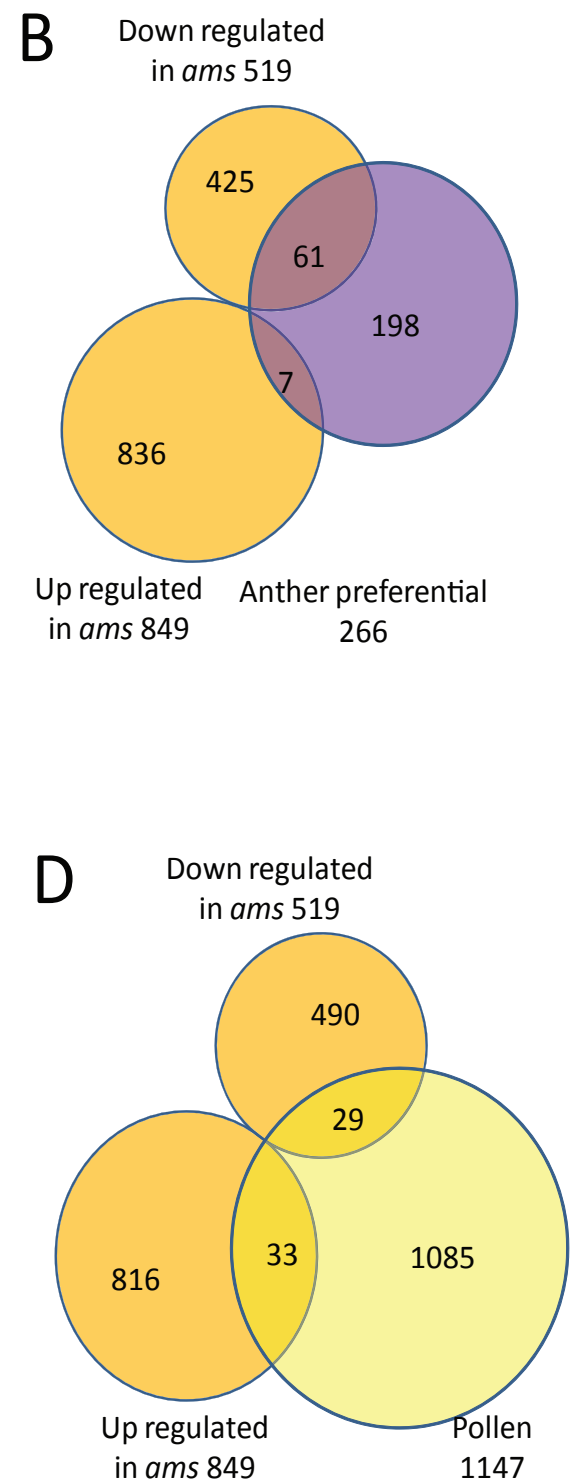

Figure 4 Venn diagrams of microarray results and previous related study. (A) A comparison of anther preferential genes identified in our study with previously known pollen genes and stamen genes. (B-D) Comparisons between genes differentially expressed in the ams anther and those preferentially expressed in certain organ: anther preferential, stamen and pollen respectively.

(5\%) (Figure 4C \& 4D, Additional file 2). The results were consistent with our hypothesis that AMS regulates genes with important functions in male-reproductive organ where they have higher expression levels $[1,8]$.

Genome-wide analysis of gene expression during early anther development by comparing anther transcriptomes of male sterile mutants, spl, ems1, and ams

Previous studies revealed essential roles of SPL and EMS1 in early anther development and ATH1 microarray data from anthers of these mutants at stage 4-6 were collected and analyzed [32]. To obtain a better overview of early anther development, we analyzed the anther transcriptome data from this study with those of $s p l$ and ems1 (detailed methods applied to all microarray data is described in experimental procedures). 1,813 and 802 genes were identified as differentially expressed in spl and ems1, respectively, contributing to a total of 3,058 genes that were differentially expressed by 2 -fold or more between the wild-type anther and one or more of the spl, ems 1 and ams mutant anthers (Additional file 7). Using the $\log _{2}$ values of the ratio of expression of the differentially expressed genes, hierarchical clustering was carried out to obtain heat-maps (Figure 5A). The patterns of $s p l$ and ems 1 were similar whereas ams had a different pattern, consistent with the fact that the 


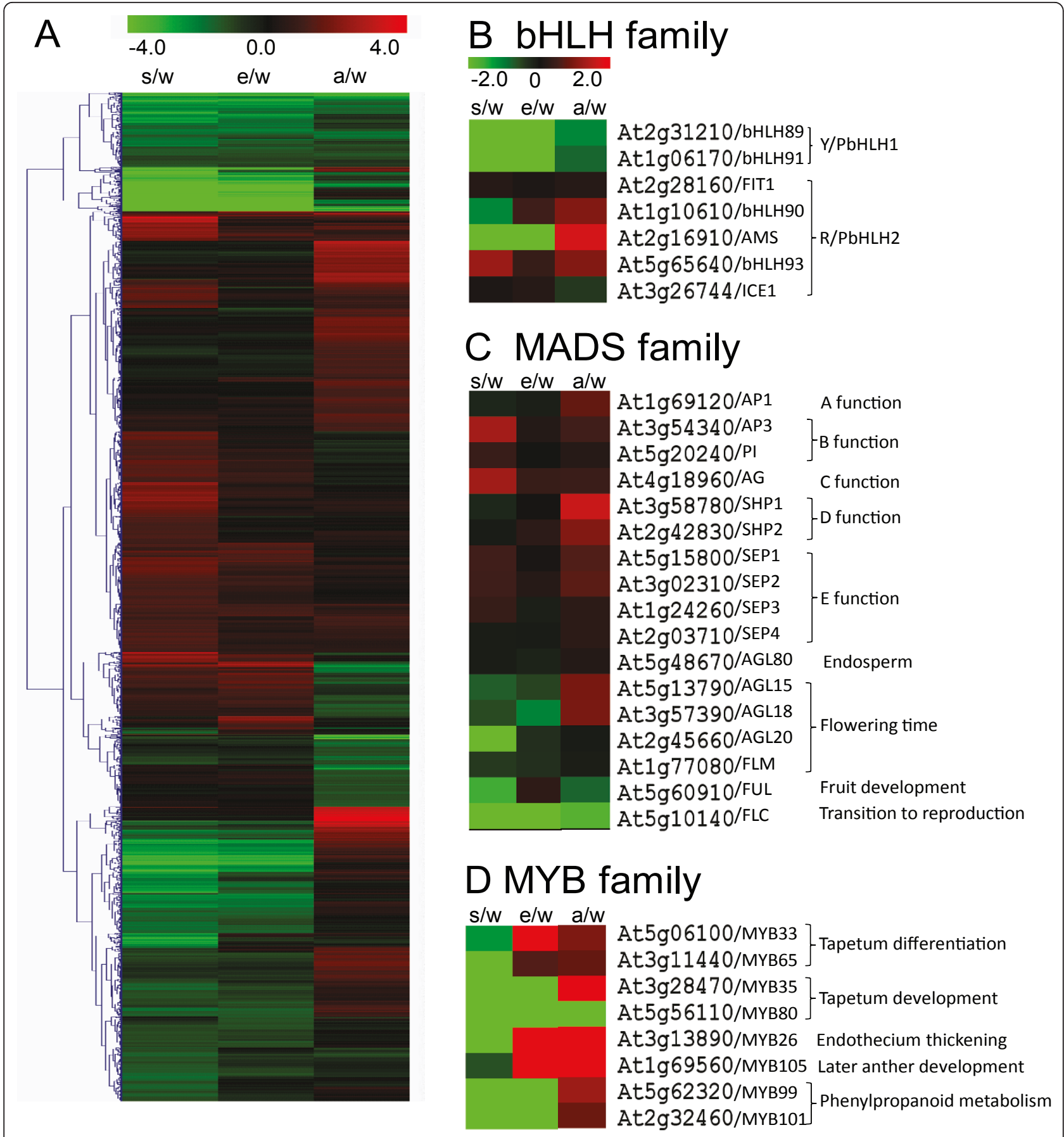

Figure 5 Expression distribution of all genes differentially expressed and specific gene families. (A) Hierarchical clustering of genes differentially expressed in at least one mutant. (B-D) Heat-map of bHLH, MADS, MYB genes with putative or known function in male-reproductive development. The number indicate logarithm ratio of the fold change in mutant compared with wild-type anther. " $W$ " represents wild-type anther and "s", "e" and "a" represents spl, ems 1 and ams. Red color represents genes which have higher expression level in mutants and green indicates reduced expression.

tapetum layer is absent in both $s p l$ and $e m s 1$ but is formed in the ams anther.

In addition, we compared the direction of differential gene expression by pair-wise comparison between different mutants, as shown in Venn diagrams (Figure 6A-D) and found that many more genes showed changes in the same direction in all three mutants than genes with changes in the opposite direction, suggesting that 

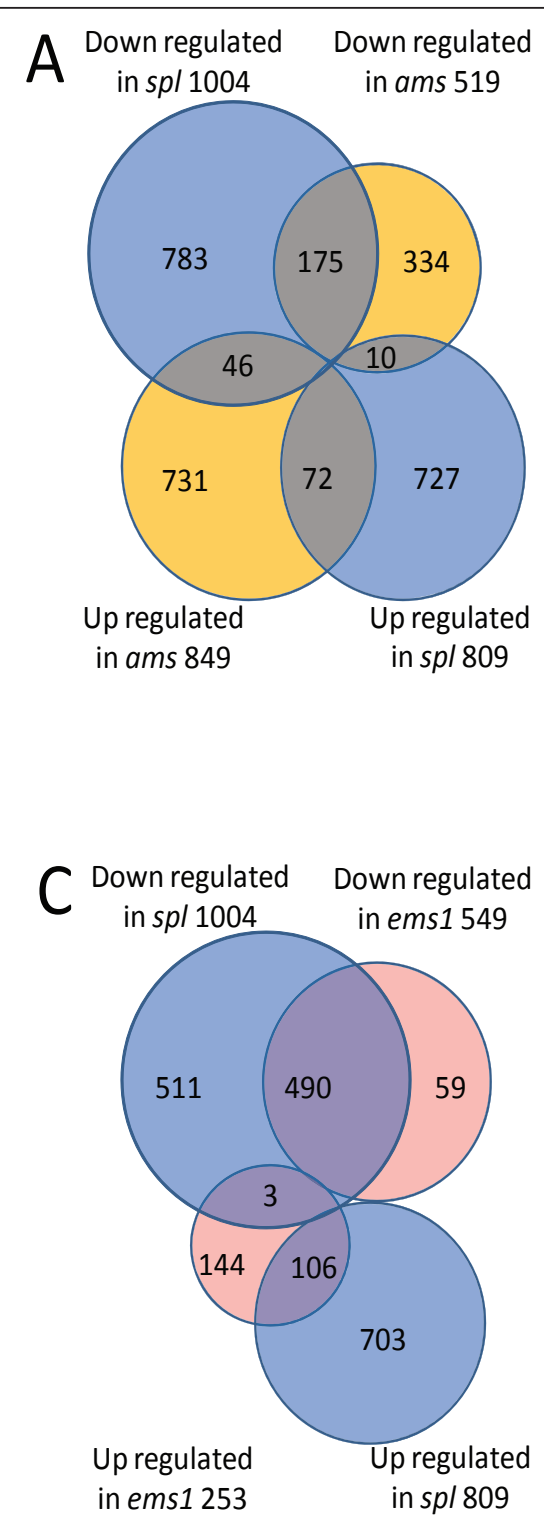
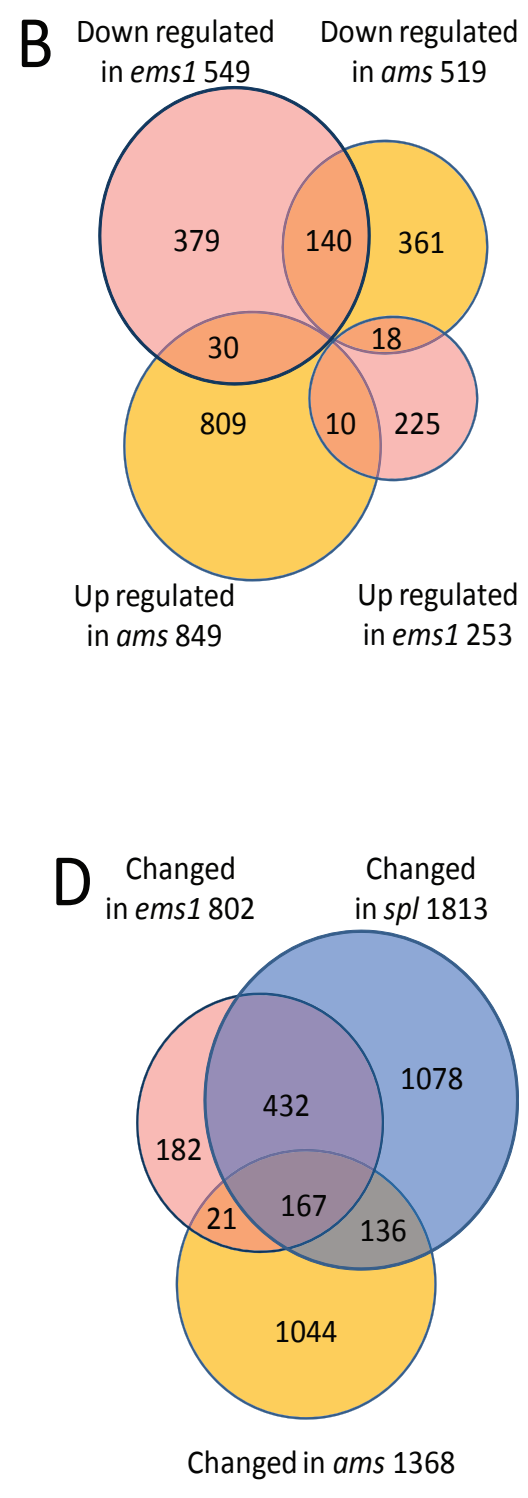

Figure 6 Comparisons between transcriptome information from three mutants. (A-C) Genes differentially expressed in three mutants respectively compared with wild-type anther have been identified and then compared with each other pairwisely. (D) Comparison of genes differentially expressed in three mutants compared with wild-type.

the three transcription factors had similar effects on some of the target genes. We also found that the nonoverlapping (differentially expressed in one mutant, but not in either of the other two) percentage of differentially expressed genes in ams (76\%) is larger than those in $s p l$ and ems1 (59\% \& 23\%, respectively, Figure 6D), providing strong evidence at the transcriptome level that the AMS function was distinct from those of SPL and EMS1 and likely regulates late gene expression in anther development, consistent with other studies [23].

Because the three mutants showed related but distinct phenotypes, we speculate that the functions of genes differentially expressed in these mutants might differ from each other. Thus we applied GO categorization of molecular function to genes up- or down-regulated in each mutant (in Additional file 3). First, genes annotated to have "other binding activities" and "other enzyme activities" were significantly enriched in categories with reduced expression in each mutant $(P$-value $<0.05)$, consistent with previous knowledge of dynamic metabolism in tapetum cells. In addition, genes encoding transcription factors and DNA binding proteins are enriched in categories with both up-and down-regulated genes in the $s p l$ mutant, suggesting that SPL control anther development at least in part by regulating genes encoding transcription factors. Furthermore, the ams mutant showed 
reduced expression of many genes encoding structural proteins, which mainly contribute to cell structural integrity, suggesting that AMS might activate these genes to promote maturation of tapetum cells.

\section{SPL and EMS1 might control tapetum development by activating AMS-dependent gene expression}

To gain a better understanding of genes that may function together in anther development, we divided the 3,058 genes into different clusters based on their expression patterns. Totally 136 genes had repressed expression in all three mutants (Additional file 7). Since tapetum cells are either absent or dysfunctional in the mutants, we expected that the expression of tapetum-related genes would reduce significantly. Previous studies indicated that tapetal cells were primarily involved in nutrition and material provision for pollen maturation [2]. Consistent with this notion, genes encoding enzymes in this group (21.8\%) are obviously over-represented comparing with all genes on ATH1 chip (10.1\%). Besides, genes belonging to the other binding category were also enriched in this group (16.4\% V.s 9.9\%, Additional file 3).

Among these genes, many of them are involved in biosynthesis of pollen wall-related compounds, such as lipids, lignin and flavonoids. A recent study showed that the loss of acyl-CoA synthetase, GhACS1, which might be involved in biosynthesis and transfer of lipids, can lead to male sterility in cotton [55]. The expression levels of 8 Arabidopsis genes involved in the lipid metabolism pathway were significantly reduced in the three mutants, suggesting their potential roles in metabolism in tapetal cells (Table 2). Besides, we found that the expression levels of 30 genes involved in endomembrane system decreased in all mutants (Table 3). Recent studies in plants suggested that many endomembrane proteins might be involved in trafficking thus influencing signal transduction and development [56-58]. Based on the observation of tapetum defects in all three mutants $[10,17,22]$, we speculate that genes sharing similar expression patterns might be important for maintaining the tapetum identity.

In addition, five genes for potential transcription factors were also found in this category (Table 4). Among them, At5g58610 and AGL25/At5g10140 are A-P genes. At5g58610 has a putative function in pathogen defense reaction, uncovering a possible factor in both anther development and external biotic stress response pathways [59,60]. AGL25, also known as $F L C$, is a repressor of flowering and its expression is epigenetically regulated

Table 2 Genes significantly down-regulated in all three mutants are involved in metabolism of pollen wall formation, including lipid, pectin, lignin and exine

\begin{tabular}{|c|c|c|c|c|c|c|}
\hline AGI & wt & $s / w$ & $e / w$ & $a / w$ & Function & Expression \\
\hline \multicolumn{7}{|c|}{ lipid related } \\
\hline At5g61320 & 8.7 & -3.9 & -3.6 & -2.2 & \multirow[t]{2}{*}{ cytochrome P450 - like protein } & $A-S$ \\
\hline At5g08250 & 8.9 & -4.5 & -4.1 & -1.4 & & \multirow[t]{7}{*}{$A-P$} \\
\hline At1g06250 & 7.6 & -3.2 & -3.0 & -1.8 & lipase-like protein & \\
\hline At5g62080 & 13 & -7.4 & -5.2 & -4.2 & \multirow[t]{5}{*}{ lipid-transfer protein } & \\
\hline At3g07450 & 12.8 & -7.5 & -5.6 & -5.2 & & \\
\hline At3g52130 & 12.9 & -7.4 & -6.0 & -3.3 & & \\
\hline At5g07230 & 10.2 & -8.1 & -6.5 & -2.7 & & \\
\hline At5g52160 & 10.7 & -6.3 & -6.2 & -1.7 & & \\
\hline \multicolumn{7}{|c|}{ pectin } \\
\hline At3g24230 & 7.6 & -3.2 & -3.2 & -3.2 & \multirow[t]{2}{*}{ pectate lyase } & \multirow[t]{3}{*}{$A-P$} \\
\hline At4g22080 & 8.5 & -4.9 & -4.6 & -1.5 & & \\
\hline At1g75790 & 10.2 & -5.8 & -5.5 & -1.9 & pectinesterase like protein & \\
\hline At3g01270 & 6.2 & -1.2 & -1.2 & -1.1 & putative pectate lyase & \multirow[t]{2}{*}{$R-P$} \\
\hline At5g50030 & 6.5 & -1.3 & -1.1 & -1.4 & pectin methylesterase inhibitor & \\
\hline \multicolumn{7}{|c|}{ lignin } \\
\hline At1g76470 & 10.3 & -4.8 & -5 & -2.3 & putative cinnamoyl-CoA reductase & $A-P$ \\
\hline At3g21230 & 7.7 & -3.1 & -3.1 & -1.8 & 4-coumarate-CoA ligase 2 & \\
\hline \multicolumn{7}{|c|}{ exine } \\
\hline At3g13220 & 10 & -5.9 & -5.7 & -2.2 & WBC27 white-brown complex & $A-S$ \\
\hline At4g14080 & 12.5 & -8.1 & -7.1 & -3.8 & maternal effect embryo arrest 48 & \multirow[t]{2}{*}{$A-P$} \\
\hline At1g02050 & 11.6 & -4.6 & -4.7 & -1.9 & LESS ADHESIVE POLLEN 6 (LAP6) & \\
\hline
\end{tabular}


Table 3 Genes related to endomembrane system affected by SPL, EMS1 and AMS

\begin{tabular}{|c|c|c|c|c|c|c|}
\hline AGI & wt & $s / w$ & $e / w$ & $a / w$ & Function & Expression \\
\hline At5g24820 & 10 & -5.7 & -5.4 & -2.1 & cnd41 & A-S \\
\hline At3g23770 & 9.9 & -5.2 & -5.3 & -2.7 & beta-1,3-glucanase, putative & \\
\hline At1g28375 & 9.7 & -5.4 & -5.1 & -2.3 & & \\
\hline At3g21620 & 7.2 & -2.7 & -2.5 & -2.1 & & \\
\hline At4g30040 & 6.6 & -2.0 & -2.1 & -1.1 & cnd41 & \\
\hline At2g24800 & 8.1 & -4.2 & -4.2 & -2.3 & peroxidase & $A-P$ \\
\hline$\overline{\text { At1g61070 }}$ & 10.2 & -6.1 & -5.7 & -1.1 & defensin & \\
\hline At4g14080 & 12.5 & -8.1 & -7.1 & -3.8 & A6 anther-specific protein & \\
\hline At1g75790 & 10.2 & -5.8 & -5.5 & -1.9 & pectinesterase like protein & \\
\hline At4g20420 & 11.7 & -6.0 & -5.4 & -3.1 & tapetum-specific A3 & \\
\hline At1g76470 & 10.3 & -4.8 & -5.0 & -2.3 & cinnamoyl-CoA reductase & \\
\hline At2g21430 & 10.9 & -4.5 & -4.1 & -2.1 & cysteine proteinase & \\
\hline At1g02640 & 11.4 & -2.0 & -2.1 & -1.2 & beta-xylosidase & \\
\hline At1g04645 & 9.6 & -5.3 & -3.3 & -3.4 & & \\
\hline At2g15120 & 8.2 & -4.1 & -3.4 & -4.3 & & \\
\hline At4g20050 & 9.9 & -5.3 & -5.0 & -1.6 & & \\
\hline At5g04820 & 8.8 & -1.6 & -2.2 & -1.2 & & \\
\hline At4g29980 & 11.5 & -5.9 & -5.1 & -4.1 & & \\
\hline At1g22015 & 10.0 & -4.1 & -3.8 & -2.7 & & \\
\hline At1g28710 & 9.4 & -4.0 & -4.1 & -2.3 & & \\
\hline At5g18290 & 9.2 & -2.3 & -2.3 & -1.7 & SIP1 & R-P \\
\hline At4g32105 & 8.1 & -2.4 & -2.5 & -2.3 & & \\
\hline At1g49490 & 6.6 & -1.7 & -1.9 & -2.0 & & \\
\hline At1g32170 & 7.4 & -1.1 & $\begin{array}{c}-1.3 \\
\end{array}$ & -1.2 & endoxyloglucan transferase & \\
\hline At4g16563 & 6.9 & -1.4 & -1.0 & -1.2 & nucleoid DNA-binding & \\
\hline At5g50030 & 6.5 & -1.3 & -1.1 & -1.4 & pollen-specific protein & \\
\hline At5g45880 & 7.1 & -1.3 & -1.0 & -1.3 & Ole e I & \\
\hline At5g44380 & 5.9 & -1.2 & -1.2 & -1.7 & reticuline oxidase precursor & \\
\hline At5g14300 & 5.8 & -1.4 & -1.3 & -1.3 & prohibitin - like protein & \\
\hline At5g12940 & 8.3 & -2.0 & -2.1 & -1.1 & leucine rich repeat protein & \\
\hline At5g09520 & 5.9 & -1.9 & -2.0 & -1.8 & surface protein PspC-related & \\
\hline At3g06300 & 9.8 & -2.1 & -1.3 & -1.1 & 4-hydroxylase alpha subunit & \\
\hline At1g60390 & 9.4 & -2.0 & -2.3 & -1.2 & polygalacturonase isoenzyme & \\
\hline At3g05930 & 6.7 & -1.4 & -1.3 & -1.2 & germin-like protein & \\
\hline At1g02790 & 6.2 & -2.0 & -1.7 & -1.5 & polygalacturonase & \\
\hline At5g09730 & 8.2 & -3.8 & -2.7 & -1.9 & beta-xylosidase & \\
\hline At5g51950 & 8.2 & -4.2 & -4.1 & -1.3 & mandelonitrile lyase & \\
\hline At1g30760 & 7.4 & -3.5 & -3.3 & -3.1 & reticuline oxidase-like protein & \\
\hline At1g22890 & 7.7 & -2.9 & -1.1 & -1.9 & & \\
\hline At1g33055 & 7.8 & -1.9 & -1.9 & -2.5 & & \\
\hline At1g49500 & 9.3 & -1.4 & -1.5 & -1.7 & & \\
\hline At3g22640 & 7.6 & -3.0 & -1.6 & -3.1 & & \\
\hline At4g15750 & 6.4 & -1.2 & -1.2 & -2.1 & & \\
\hline
\end{tabular}


Table 4 Transcription factors in SEA-L and SE-L cluster with known or putative function in anther development

\begin{tabular}{|c|c|c|c|c|c|c|c|}
\hline Cluster & AGI & wt & $s / w$ & $e / w$ & $a / w$ & Function & Expression \\
\hline \multirow[t]{5}{*}{ SEA-L } & At5g58610 & 7.7 & -1.6 & -1 & -1.9 & PHD finger & $A-P$ \\
\hline & At5g10140 & 8.1 & -3.2 & -3.1 & -1.8 & AGL25 & \\
\hline & At4g36590 & 5.8 & -1.7 & -1.4 & -1.7 & AGL40 & $R-P$ \\
\hline & At2g22800 & 8.7 & -2.9 & -2.0 & -1.3 & HAT9 & \\
\hline & At5g56110 & 7.5 & -1.6 & -1.5 & -1.8 & MYB 80/MYB103 & \\
\hline \multirow[t]{18}{*}{ SE-L } & At1g06170 & 9.6 & -5.9 & -4.6 & -0.8 & bHLH89 & $A-P$ \\
\hline & At3g28470 & 8.6 & -4.9 & -4.5 & 0.0 & TDF1/MYB35 & \\
\hline & At2g31210 & 7.1 & -3.4 & -2.9 & -1.1 & bHLH91 & \\
\hline & At3g57370 & 7.3 & -2.8 & -2.8 & 0.8 & initiation factor IIB & $R-P$ \\
\hline & At1g77850 & 8.8 & -2.4 & -1.7 & -0.1 & auxin response factor & \\
\hline & At2g28830 & 6.5 & -1.1 & -1.1 & 0.3 & transcription activator & \\
\hline & At5g62320 & 8.6 & -3.3 & -3.4 & -0.3 & MYB99 & \\
\hline & At4g09460 & 8.7 & -3.4 & -2.3 & 0.8 & MYB6 & \\
\hline & At4g34680 & 9.3 & -2.6 & -1.2 & 0.3 & GATA 3 & \\
\hline & At2g41630 & 10.6 & -1.1 & -1.4 & -0.7 & TFIIB & \\
\hline & At3g10580 & 7.3 & -2.5 & -2.3 & 0.9 & MYB & \\
\hline & At5g61590 & 9.7 & -2.3 & -1.6 & -0.3 & AtERF107 & \\
\hline & At4g37790 & 8.1 & -1.9 & -1.8 & -0.8 & HAT22 & \\
\hline & At4g34990 & 8.5 & -1.3 & -2.2 & -0.6 & MYB32 & \\
\hline & At4g10920 & 8.0 & -1.9 & -1.8 & -0.5 & transcriptional co-activator & \\
\hline & At1g66160 & 7.0 & -2.8 & -2.0 & -0.5 & PHOR1 like & \\
\hline & At5g65790 & 7.5 & -3.7 & -3.2 & -0.1 & MYB68 & \\
\hline & At4g34000 & 7.7 & -1.8 & $\begin{array}{c}-1.4 \\
\end{array}$ & -0.2 & OBF3 & \\
\hline
\end{tabular}

All the expression values are log2 ratio. SEA-L includes genes whose expression levels were reduced in all three mutants. SE- $L$ include genes whose expression levels were reduced in both $\mathrm{spl}$ and ems 1 mutants.

[61]. However, its possible function in anther development is not known. Three others were AGL40/ At4g36590, MYB80/At5g56110 and HAT9/At2g22800. $A G L 40$ was found in the proliferative endosperm transcriptome and MYB80/At5g56110 in tapetum development [27]. These results suggested that normal tapetum functions might require multiple transcription factors preferentially expressed in the anther downstream of AMS.

SPL and EMS1 can regulate early anther development by AMS-independent pathways

Moreover, 354 genes showed reduced expression in $s p l$ and ems 1 but not in ams (Additional file 7), including the enrichment of the categories of hydrolase activity (15.5\% vs. $8.4 \%)$, other binding activity (19.5\% vs. $9.9 \%)$, and other enzyme activity (18.0\% vs. $10.1 \%)$. Among the genes in this cluster, four genes: MS2, ACOS5, $C Y P 703 A 2$ and $A 7$, were involved in sporopollenin monomer biosynthesis, the lack of which leads to male sterility (Table 1) $[62,63]$. Since these genes were not affected in the ams mutant, some lipid metabolic genes might be activated independent of AMS and they might exert functions earlier than AMS or in parallel to AMS $[63,64]$.

Besides, several genes encoding putative transcription factors were found within this subset (Table 4). A-P genes with known functions, such as TDF1/At3g28470 (or MYB35) and bHLH89/At1g06170, were also identified in this category $[24,32,35]$. TDF1 is essential to the tapetum function controlling callose dissolution and acts downstream of SPL and upstream of AMS and MYB103 (Table 4) [24]. Our data also support the regulatory hierarchy of SPL-TDF1-AMS.

The expression of $A M S$ is significantly reduced in $s p l$, therefore we assumed that genes down-regulated in ams should have similar reduction in $s p l$. Interestingly, we found that 56 genes showed opposite expression changes in $s p l$ and in ams compared with wild type anther, and even larger proportion (1,065 genes) only differentially expressed in ams (Figure 6A). Another gene with reduced expression in $s p l$ and ems 1 mutants is DYT1, which encodes a bHLH protein similar to AMS [22]. It is possible that SPL might also regulate anther development through pathways independent of AMS, such as those requiring DYT1 function [22]. We speculate that SPL 
might activate other transcription factors that affect AMS-regulated genes in contrast to the function of AMS (represented by factors $x$ and $\mathrm{Y}$ in Figure 7). The effects of AMS reduction in $s p l$ might be outweighed by the loss of $\times$ or $Y$; such regulatory interactions would explain the opposite expression changes in $s p l$ and ams. The identification and understanding of the proposed factors will require further investigations.

\section{AMS-dependent and independent anther expression of genes encoding transcription factors \\ Expression of $\mathrm{bHLH}$ genes during anther development}

Since many transcription factors have been found to play key roles in regulating anther development, we analyzed our anther transcriptome profiles by focusing on transcription factor gene families $[5,28,65]$. To identify additional candidate genes for anther development, we analyzed all 147 known bHLH genes in Arabidopsis (Additional file 8) [40]. For several clades according to the most recent phylogeny trees of bHLH family $[40,66,67]$, including the clade that includes AMS, all or most members of the same clade were expressed similarly in the anther (Additional file 8), suggesting conserved functional roles in anther development. For example, bHLH91 and bHLH89 shared similar reductions in all three mutants, suggesting possible redundant functions in the anther (Figure 5B).
In other cases, the closely related homologs did not share similar expression patterns in mutant vs. wild type anthers (Additional file 8). For example, bHLH93 is a close homolog of $A M S$; but unlike $A M S$, it was preferentially expressed in the inflorescence compared with the anther. Also unlike $A M S$, it was elevated in expression in $s p l$. It is possible that some compensatory mechanisms might act to increase transcription of bHLH93 when $A M S$ is mutated (Figure $5 \mathrm{~B}$ ).

In addition, some bHLH genes with known functions in other organs showed increased expression in the $s p l$ mutant, suggesting that $S P L$ acts to maintain the identity of male reproductive organ by reducing the expression of genes needed for other organs. For example, ZCW32 (bHLH31) controls petal formation and was activated in the $s p l$ anther $[68,69]$, suggesting that SPL can promote the normal anther development at an early stage by repressing some genes normally expressed in nearby whorls.

Possible role of MADS-box genes in anther development

Genes of the MADS-box family have been extensively studied in Arabidopsis, because they were first identified as flower homeotic genes that determine floral organ and meristem identities [70,71]. Till now, more than one hundred MADS-box genes have been identified, 79 of which were found to be present in our anther microarray data but most were non-anther-specific (Additional file 7 \&

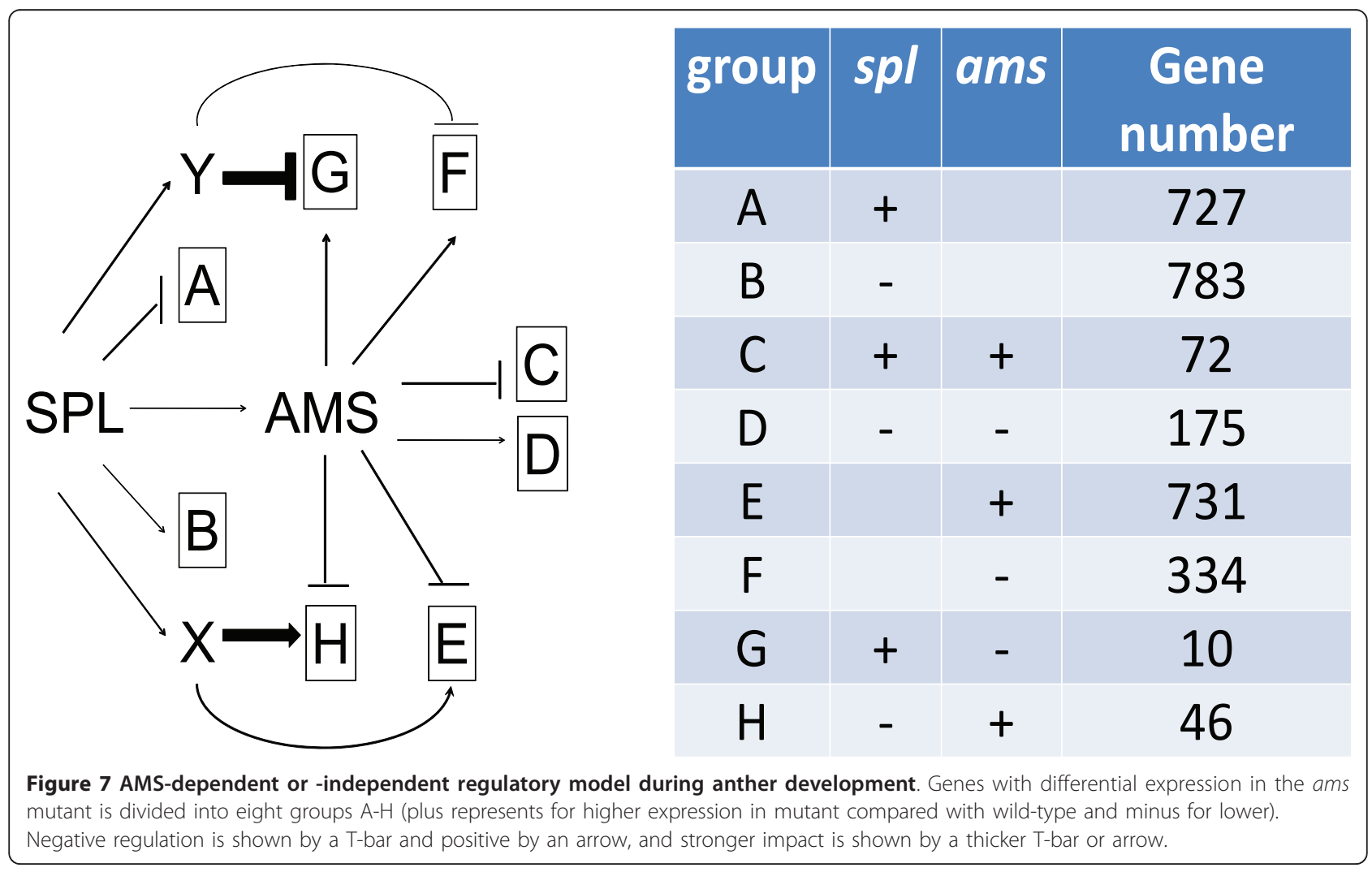


Additional file 8) [70]. Except for APETALA2 (AP2), majority of genes involved in the ABCDE model belong to the MADS family [71]. They are mostly inflorescence-preferential rather than anther-specific genes from the comparison of microarray data as described above. APETALA1 (AP1) is an A function gene controlling the first and second whorls and no expression shift was observed [72]. APETALA3 (AP3) and PISTILLATA (PI) are both B function genes, essential for the formation of petals and stamens [72-74]. Interestingly, their expression patterns were different. $P I$ is an anther-preferential gene, but its expression level did not change in any mutant while $A P 3$ was obviously up-regulated in spl, suggesting that AP3 is regulated more tightly than $P I$ during anther development. $A G$, the $C$ class gene controlling both stamen and carpel identities, shared similar expression patterns in the anther with AP3 [13], supporting a role of $A G$ in anther development after the specification of stamen identity (Figure $5 \mathrm{C}$ ).

Moreover, D class genes, including STK/AT4g09960, SHP1/At3g58780 and SHP2/At2g42830 , are important for ovule development $[75,76]$. Although the expression of D class genes was relatively low, we observed increased expression of SHP1 in the ams mutant, suggesting a possible negative regulatory role of AMS in ovule development. On the other hand, E class genes, SEP1, SEP2, SEP3 and SEP4, which are homologs that have redundant functions, had different expression pattern in the anthers. SEP1 and SEP2 were activated in $s p l$ and $a m s$, whereas SEP3 and SEP4 did not change much (Figure 5C).

Beside the $\mathrm{ABCDE}$ genes, some other MADS genes were also expressed in the anther (Additional file 8). The expression levels of known flowering-time related genes (FLM, AGL15, AGL18 and AGL20) [77-79] were reduced in $s p l$ and ems 1 slightly. FUL involved in fruit development [80] was up-regulated in the $s p l$ and ems1 mutants, suggesting negative roles of SPL and EMS1 in whorl 4. AGL80, important for central cell and endosperm formation in female gametophytes [81], was also reduced in all three mutants, suggesting a possible role in male gametophyte (Additional file 8).

\section{Differential expression of MYB genes in three mutants}

In addition to the bHLH and MADS-box families, other gene families are also involved in anther development. As the largest Arabidopsis transcription factor family, $M Y B$ genes play important roles in controlling many cellular processes, such as secondary metabolism, morphogenesis, and signal transduction (Additional file 8) [82]. Previous studies revealed a number of roles of MYB genes in early anther development (Figure 5D). For example, GAMYB in rice functions in anther development via GA signaling pathway [83]. In Arabidopsis, the GAMYB homologs $M Y B 33$ and MYB65 also share a redundant function regulating tapetum differentiation $[22,27,84,85]$. Our microarray results indicated that expression of $M Y B 33$ and MYB65 was reduced only in $s p l$, not in the other two mutants, implying that the functions of MYB33 and $M Y B 65$ are independent of EMS1 or AMS.

In addition, MYB35/TDF1 and MYB80/MYB103 controlling callose dissolution and exine formation [27] were reduced in $s p l$ and $e m s 1$, and $M Y B 80$ was also down-regulated in ams, suggesting that it acts downstream of $A M S$. Moreover, the MYB99 and MYB101 genes that regulate phenylpropanoid metabolism [31] showed a similar expression pattern to that of MYB35/TDF1. MYB26/MS35 and MYB105 are closely related homologs; both were down-regulated in $s p l$ but up-regulated in ams. Previous study suggested that MYB26 is required for endothecium thickening and anther dehiscence [86]. RNA in situ hybridization revealed that MYB105 as well as MYB101 are expressed in late tapetum $[86,87]$, consistent with our findings of the changes of their expression in the mutant anthers.

\section{Expression of WRKY, bZIP, AP2/ERF and NAC genes}

The WRKY family contains at least 72 members in Arabidopsis [42] and has diverse functions, such as abiotic and biotic stress response, hormone signaling pathway, immune response and development in plants [88]. However, it is not known whether WRKY genes are important for flower development. Here we compared the expression of all WRKY genes on the ATH1 chip and found that 29 of them were expressed in the anther (Additional file 8), with the highly similar WRKY2/At5g56270 and WRKY32/ At4g30935 [88] being anther-preferential. Moreover, WRKY2 was down-regulated in $s p l$, suggesting that it might function downstream of SPL in anther development.

We also analyzed bZIP, ERF and NAC families of transcription factors. Like the WRKY family, most genes in these families do not have known functions in reproductive development (Additional file 8). However, we found several of them were differentially expressed in the anthers of male sterile mutants, suggesting they are components of a complex transcriptional network regulating anther development.

Transcriptional regulatory network for anther development Genetic studies and our transcriptomic analyses reported here support an emerging transcriptional network (Figure 8). Previous molecular genetic studies showed that SPL up-regulates the expression of EMS1 and DYT1, which are upstream of AMS [22,23], as well as other genes encoding transcription factors shown to be important in anther development [8]. SPL also negatively regulates the expression of $B$ and $C$ function genes in the anther, as well as some genes that are normally expressed in petals and carpals, probably to prevent anther from developing traits of other floral organs. 


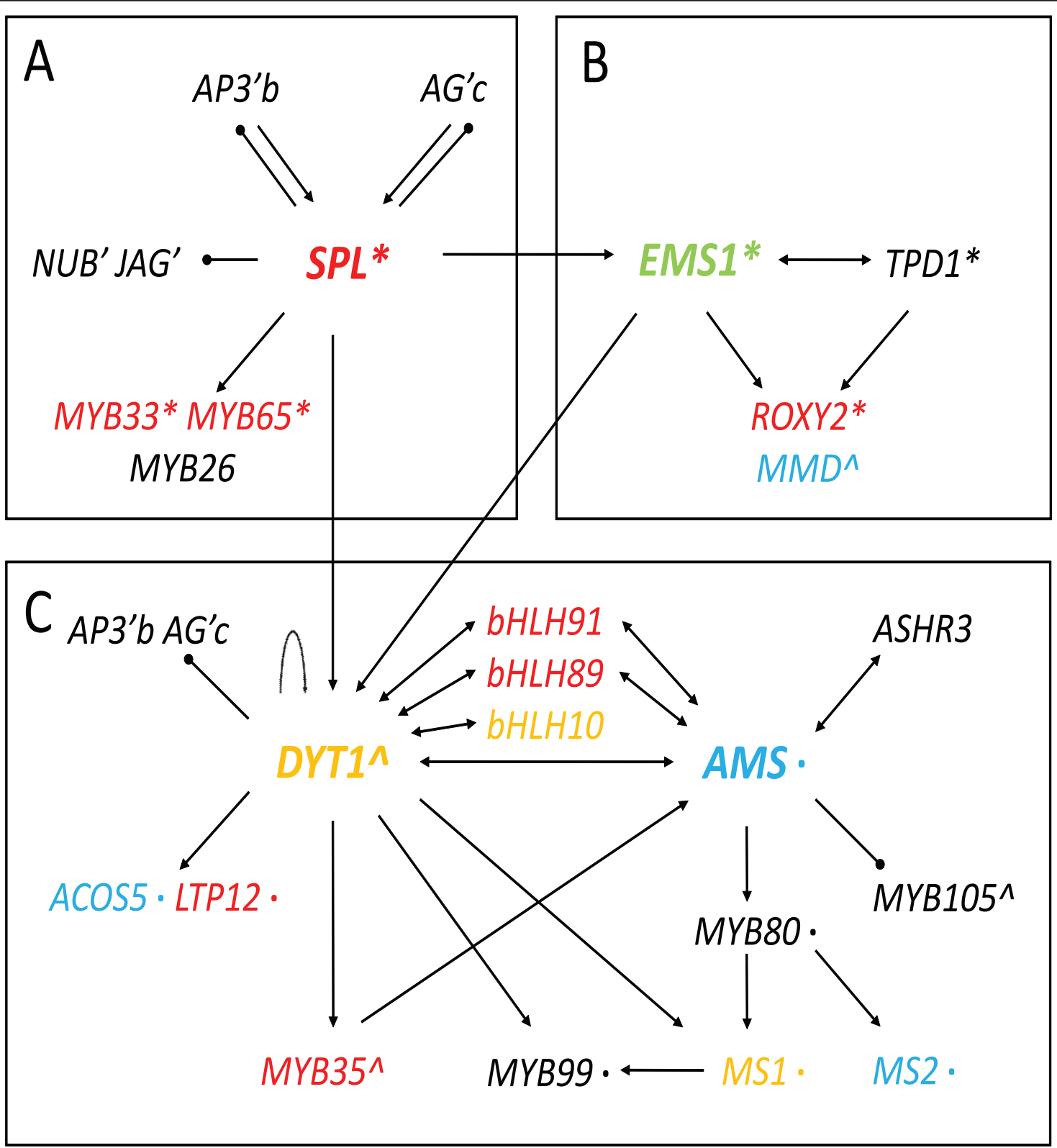

Figure 8 Gene regulatory network of anther development during early stages. Gene regulation is represented by T-bars (negatively) and arrows (positively). The direct regulation confirmed by experiment is represented in bold line. Genes encoding proteins with interaction is represented by double arrows. Gene expression patterns in different tissues are shown by colors (blue for anther specific; red for antherpreferential; green for reproductive-preferential and yellow for genes not included in ATH1 chip). Gene function in tapetum formation is marked by an apostrophe; in pollen wall formation by an asterisk; in callose dissolution by double asterisks; in stamen and petal formation by the letter b; in stamen and carpel formation by the letter $\mathrm{c}$.

In addition, the key position of $S P L$ in anther regulatory hierarchy as indicated by genetic studies is supported by its effects on the anther transcriptome (Figure 8A).

EMS1 also positively regulates the expression of DYT1 [32]. EMS1 was shown to interact with its putative ligand TPD1 [18], thereby regulating genes essential for the differentiation of tapetum cells. In addition, some genes important for meiosis are also affected in the ems1 mutant. For example, the MMD and ROXY2 genes that are important in anther lobe formation and meiosis, respectively, were significantly reduced in ems 1 (Figure 8B).

$A M S$ was down-regulated in $s p l$ and ems1 according to the microarray data. Because DYT1 and AMS are related bHLH proteins, which are known to form homodimers or heterodimers with other bHLH proteins, we 
propose that they probably regulate the expression of different genes by forming different complex with other proteins. DYT1 is also a putative candidate that exerts opposite function as $\times$ and/or Y downstream of SPL in anther development by interact with different proteins (Figure 8C). This proposed transcriptional regulatory network of anther development is based on information from genetics, transcriptomics, and phylogenetics studies (Figure 8A-C). The hypothesized interactions, including the roles of some functionally redundant genes, could be tested by further experiments.

\section{Conclusion}

In this study, we identified genes whose expression was changed in spl, ems 1 and ams at anther stage 4-7 and further categorized these genes according to their expression patterns. These genes might directly regulate some fundamental biological processes during anther development. In addition, both anther-specific and nonanther-specific genes are identified in anther development. Transcriptome analyses also showed AMS-dependent and -independent pathways. Careful analyses of transcriptome combined with genetic and phylogenetic information revealed an elaborate regulatory network during early anther development and expanded our understanding of the hierarchy of anther-developmentrelated genes, especially transcription factors.

\section{Methods}

\section{Plant materials}

All the plants in this study were grown in soil under long day condition $\left(16 \mathrm{~h} \mathrm{light} / 8 \mathrm{~h}\right.$ dark) at constant $22^{\circ} \mathrm{C}$. The wild-type in this paper refers to ecotype Landsberg erecta (L er). The mutants of $s p l$, ems 1 are of L er background as described [22,32], while the ams mutant is of Columbia background. We select 21-28 day old plant to collect anther at 4-7 stage as described previously [32].

\section{Microarray experiment}

Following the Affymetrix GeneChip Expression Analysis Overview described on the website [35], cRNA was synthesized for hybridization as described [32]. Hybridization, washing, staining, scanning and data collection were performed at the Genomics Core Facility, Pennsylvania State University, University Park.

\section{Microarray analysis to identify differentially expressed genes in anther of mutants}

Normalization was applied using Bioconductor package in R by RMA [43], and all expression values were converted to logarithms base 2. LIMMA library was then used to compare signals from mutant and wild-type anther. Only genes with more than two-fold changes were selected. To obtain more reliable result, we screened out genes with q-value (FDR) larger than 0.05, since q-value is more stringent than p-value of $T$-test based on previous study [89].

Similar data processing was performed with the microarray results from different organs. The microarray data from all organs in wild-type Arabidopsis were normalized together and converted to logarithms base 2 values. We defined genes as anther-specific if they met these criteria: 1) the expression in anther is significantly higher than in any other tissue with FDR $<0.05 ; 2$ ) gene is present in anther but absent in any other tissues. We used two alternative methods to define whether a gene is present in a tissue. One of the methods was using the Affymetrix' MAS5 algorithm. This method uses a comparison of hybridization intensity with wild-type oligo set vs mismatched oligo set; sometimes similar levels of hybridization to both sets can actually be real expression, yet such results would lead to "absent" calls. Therefore, we also used a second method to define "presence", by using a threshold of 50 for expression value, previously determined on basis of analysis of variation among samples of the same tissue $[32,43]$. Both results are shown in Additional file 5.

For the anther-preferential genes, we used the criteria that the expression in anther is 1) present using both MAS and/or 50 cutoff; 2) significantly higher than in any other tissue with FDR $<0.05 ; 3$ ) at least 2 fold more compared with any other tissues. The reproductive-preferential genes required the expression present and significantly higher in anther than only the vegetative organs using FDR $<0.05$ and 2 -fold changes.

Hierarchical clustering of co-expressed genes was performed by MeV 4.6 [86]. We used Euclidean distance metric to conduct this analysis. For the identification of the functions of the differentially expressed genes, the annotations of genes on ATH1 microarray chip were downloaded from Affymetrix website and we used the GO categorization function on TAIR website [71]. To verify whether one category is enriched compared with the whole genome, we applied hypergeometric test and only the categories with p-value less than 0.05 were called statistically enriched group [90].

\section{Cis-regulatory element analysis}

Possible promoter sequences of all genes on the microarray chip (1 kb upstream of the start codon) were obtained from TAIR website. The number of common bHLH binding site (E-box) was then counted. We then plotted the fold-changes of gene expression in ams against the numbers of their putative AMS binding sites using minitab [47]. The identification of cis-regulatory binding site was conducted by perl [46]. The binding motifs were obtained from Gene Regulation and PlantCARE [70]. 


\section{Real-time PCR experiments}

To test the reliability of our microarray hybridizations, six genes and one reference (ACT2, At3g18780) were studied using Quantitative Real-Time PCR. RNA extraction and Real-Time experiments followed the protocols described previously [91]. Triplicate reactions were performed for all tissues with "no reverse transcription" as a negative control. All primer information is provided in Additional file 5. Relative transcript quantities were calculated using the $\Delta \Delta \mathrm{Ct}$ method [92].

\section{Additional material}

Additional file 1: Figure S1. Correlation coefficients between signal intensities from wild-type and the ams anther replicates. Pearson's correlation coefficients were larger than 0.96 between pair of the biological replicates from the ams and wild type anther, indicating that the results were highly reproducible. Figures S2 \& S3. GO annotation of genes up- and down-regulated in ams. $\mathrm{GO}$ categorization of genes differentially expressed in the ams mutant compared with wild type. The enriched groups were shown in different color with P-value provided. Figures S4-S11. The genes involved in different metabolic pathways that were activated or repressed in ams compared with wild type. Red color represents genes activated while green color represents genes repressed in ams compared with wild type. The overview of metabolism activities was shown in supplemental figure 4. Figure 5, 6, 7, 8-11

showed expression shifts of genes involved in secondary metabolism, regulatory pathways, receptor-like-kinase pathway, transcriptional regulation, protein trafficking, stress response, ubiquitin and autophagy dependent degradation pathway. Figure S12. Real-time PCR results consistent with microarray data. Six genes were verified using realtime PCR. The bars in blue represent the real-time RT-PCR results while red the microarray results. All the numbers shown in this figure are the fold changes of expression intensities in other tissues compared with anther. "infl" is the abbreviation of inflorescence.

Additional file 2: Genes differentially expressed in anther and inflorescences from the ams mutant. This additional file contains information about genes differentially expressed in the ams anther and inflorescences compared with wild type. Column sequence, abbreviation and the version of annotation are as those used as in table 1 and all the other supplemental tables. All expression values are log2 ratio.

Additional file 3: GO categorization of different clusters based on expression pattern. This additional file contains information about numbers of genes in each GO category. The enriched categories were highlighted in red color.

Additional file 4: Genes differentially expressed in the ams mutant with putative function in exocytosis, transportation, ubiquitination and stress reaction. This additional file contains information about genes involved in different pathways with elevated expression levels in ams.

Additional file 5: Genes defined as specifically or preferentially expressed in early anther or preferentially expressed in reproductive tissue. This additional file contains information about genes preferentially expressed in only anther or reproductive tissues compared with roots, stems, leaves, siliques.

Additional file 6: Genes expressed in stamen, early anther and pollen. This additional file contains information about the expression levels of gene in different organs.

Additional file 7: Genes differentially expressed in $s p l$, ems 1 or/and the ams mutants. This additional file contains information about the expression levels of gene differentially expressed in the three mutants.

Additional file 8: Expression pattern of MADS, MYB, $b H L H, W R K Y$, bZIP, AP2/ERF and NAC families. This additional file contains information about the expression levels of different gene families.

\section{Abbreviations}

AMS: Aborted microspores; AG: Agamous; AP2/ERF: APETALA2/ethylene response factor domain-containing transcription factor; bHLH: Basic helixloop-helix; bZIP: Basic-leucine zipper; CCR1: Cinnamoyl coa reductase1; DYT1: Dysfunctional tapetum1; EMS1: Excess male sporocytes1; EPS1: Enhanced pseudomonas susceptibilty; EXO: Exocytosis; GO: Gene ontology consortium; MADS: MCM1-agamous-deficiens-SRF; MYB: Myeloblastosis-like gene; NAC: NAM/ATAF1/2/CUC2; RD22: Responsive to dessication22; PI: Pistillata; RPK2: Receptor-like protein kinase2; SEC: Secretion; SERK1/2: Somatic embryogenesis receptor-like kinases1/2; SNARE: Soluble NSF attachment protein receptor; SPL/NZZ: Sporocyteless/nozzle; TAIR: The arabidopsis information resource web site; TIR-NBS-LRR: Toll interleukine 1receptornucleotide binding site-leucine rich repeat domain;TPD1: Tapetum determinant1; VAM3: Vacuolar morphology; VSP1: Vegetative storage protein.

\section{Acknowledgements}

We greatly appreciate the help of Dr. Craig Praul in performing microarray hybridizations. We thank Dr. Naomi Altman for discussion of statistic analysis. We also thank Ms. Jiong Wang for plant care. We appreciate the suggestion from Drs. Xiaofan Zhou, Zhenhai Zhang, Zhao Su on microarray data analysis. This work was supported by a US Department of Energy grant to $\mathrm{H}$. M. and funds from Department Biology and the Huck Institutes of the Life Sciences, the Pennsylvania State University, and Fudan University.

\section{Author details}

'Department of Biology and the Huck Institutes of the Life Sciences, the Pennsylvania State University, University Park, PA 16802, USA. ${ }^{2}$ Intercollege Graduate Program of Cell and Developmental Biology, the Huck Institutes of the Life Sciences, the Pennsylvania State University, University Park, PA 16802, USA. ${ }^{3}$ State Key Laboratory of Genetic Engineering, Institute of Plant Biology, Center for Evolutionary Biology, School of Life Sciences, Institutes of Biomedical Sciences, Fudan University, Shanghai 200433, China. ${ }^{4}$ Plant and Microbial Biology Department, University of California, Berkeley, CA 94720, USA.

\section{Authors' contributions}

HM designed and supervised the research; BF performed tissue collection and RNA isolation; XM performed data analysis; XM and HM wrote the manuscript drafts; XM, BF and HM edited the manuscript; all authors approved the manuscript.

Received: 25 August 2011 Accepted: 15 February 2012

Published: 15 February 2012

\section{References}

1. Ge X, Chang F, Ma H: Signaling and transcriptional control of reproductive development in Arabidopsis. Curr Biol 2010, 20:R988-997.

2. Scott RJ, Spielman M, Dickinson HG: Stamen structure and function. Plant Cell 2004, 16(Suppl):46-60.

3. McCormick S: Male gametophyte development. Plant Cell 1993, 5:1265-1275

4. Goldberg RB, Beals TP, Sanders PM: Anther development: basic principles and practical applications. Plant Cell 1993, 5:1217-1229.

5. Ma H: Molecular genetic analyses of microsporogenesis and microgametogenesis in flowering plants. Annu Rev Plant Biol 2005, 56:393-434.

6. Ma H, Sundaresan V: Development of flowering plant gametophytes. Curr Top Dev Biol 2010, 91:379-412.

7. Sanders P, Bui A, Weterings K, McIntire K, Hsu Y, Lee P, Truong M, Beals T, Goldberg R: Anther developmental defects in Arabidopsis thalianamalesterile mutants. Sex Plant Reprod 1999, 11:297-322.

8. Chang F, Wang Y, Wang $\mathrm{S}, \mathrm{Ma} \mathrm{H}$ : Molecular control of microsporogenesis in Arabidopsis. Curr Opin Plant Biol 2011, 14:66-73.

9. Coen E: Goethe and the ABC model of flower development. C R Acad SCi III 2001, 324:523-530.

10. Yang WC, Ye D, Xu J, Sundaresan V: The SPOROCYTELESS gene of Arabidopsisis required for initiation of sporogenesis and encodes a novel nuclear protein. Genes Dev 1999, 13:2108-2117.

11. Schiefthaler U, Balasubramanian $\mathrm{S}$, Sieber P, Chevalier D, Wisman E, Schneitz K: Molecular analysis of NOZZL, a gene involved in pattern 
formation and early sporogenesis during sex organ development in Arabidopsisthaliana. Proc Natl Acad Sci USA 1999, 96:11664-11669.

12. Jack T: Molecular and genetic mechanisms of floral control. Plant Cell 2004, 16(Suppl):S1-17.

13. Yanofsky MF, Ma H, Bowman JL, Drews GN, Feldmann KA, Meyerowitz EM: The protein encoded by the Arabidopsishomeotic gene agamous resembles transcription factors. Nature 1990, 346:35-39.

14. Ito T, Wellmer F, Yu H, Das P, Ito N, Alves-Ferreira M, Riechmann JL, Meyerowitz EM: The homeotic protein agamous controls microsporogenesis by regulation of sporocyteless. Nature 2004, 430:356-360.

15. Yang $S L$, Xie LF, Mao HZ, Puah CS, Yang WC, Jiang L, Sundaresan V, Ye D: TAPETUM DETERMINANTis required for cell specialization in the Arabidopsisanther. Plant Cell 2003, 15:2792-2804.

16. Hord CL, Chen C, Deyoung BJ, Clark SE, Ma H: The BAM1/BAM2 receptorlike kinases are important regulators of Arabidopsisearly anther development. Plant Cell 2006, 18:1667-1680.

17. Zhao DZ, Wang GF, Speal B, Ma H: The EXCESS MICROSPOROCYTESgene encodes a putative leucine-rich repeat receptor protein kinase that controls somatic and reproductive cell fates in the Arabidopsisanther. Genes Dev 2002, 16:2021-2031.

18. Jia G, Liu X, Owen HA, Zhao D: Signaling of cell fate determination by the TPD1 small protein and EMS1 receptor kinase. Proc Natl Acad Sci USA 2008, 105:2220-2225.

19. Yang $S L$, Jiang $L X$, Puah CS, Xie LF, Zhang XQ, Chen LQ, Yang WC, Ye D: Overexpression of TAPETUM DETERMINANTalters the cell fates in the Arabidopsiscarpel and tapetum via genetic interaction with EXCESS MICROSPOROCYTES1/EXTRA SPOROGENOUS CELLS. Plant Physiol 2005, 139:186-191

20. Mizuno S, Osakabe Y, Maruyama K, Ito T, Osakabe K, Sato T, Shinozaki K, Yamaguchi-Shinozaki K: Receptor-like protein kinase 2 (RPK 2) is a novel factor controlling anther development in Arabidopsisthaliana. Plant J 2007, 50:751-766.

21. Colcombet J, Boisson-Dernier A, Ros-Palau R, Vera CE, Schroeder Jl: ArabidopsisSOMATIC EMBRYOGENESIS RECEPTOR KINASES1 and 2 are essential for tapetum development and microspore maturation. Plant Cell 2005, 17:3350-3361.

22. Zhang W, Sun Y, Timofejeva L, Chen C, Grossniklaus U, Ma H: Regulation of Arabidopsistapetum development and function by DYSFUNCTIONAL TAPETUM(DYT) encoding a putative bHLH transcription factor. Development 2006, 133:3085-3095.

23. Sorensen AM, Krober S, Unte US, Huijser P, Dekker K, Saedler H: The Arabidopsis aborted microspores $(A M)$ gene encodes a MYC class transcription factor. Plant J 2003, 33:413-423.

24. Zhu J, Chen H, Li H, Gao JF, Jiang H, Wang C, Guan YF, Yang ZN: Defective in Tapetal development and function 1 is essential for anther development and tapetal function for microspore maturation in Arabidopsis. Plant J 2008, 55:266-277.

25. Boavida $L C$, Becker JD, Feijo JA: The making of gametes in higher plants. Int J Dev Biol 2005, 49:595-614.

26. Wilson ZA, Morroll SM, Dawson J, Swarup R, Tighe PJ: The Arabidopsis MALE STERILITY1(MS) gene is a transcriptional regulator of male gametogenesis, with homology to the PHD-finger family of transcription factors. Plant J 2001, 28:27-39.

27. Zhang ZB, Zhu J, Gao JF, Wang C, Li H, Zhang HQ, Zhang S, Wang DM, Wang QX, Huang $H$, et al: Transcription factor AtMYB103 is required for anther development by regulating tapetum development, callose dissolution and exine formation in Arabidopsis. Plant J 2007, 52:528-538.

28. Wilson ZA, Zhang DB: From Arabidopsisto rice: pathways in pollen development. J Exp Bot 2009, 60:1479-1492.

29. Cutler S, McCourt P: Dude, where's my phenotype? Dealing with redundancy in signaling networks. Plant Physiol 2005, 138:558-559.

30. Wellmer F, Riechmann JL, Alves-Ferreira M, Meyerowitz EM: Genome-wide analysis of spatial gene expression in Arabidopsisflowers. Plant Cell 2004, 16:1314-1326

31. Alves-Ferreira M, Wellmer F, Banhara A, Kumar V, Riechmann JL, Meyerowitz EM: Global expression profiling applied to the analysis of Arabidopsisstamen development. Plant Physiol 2007, 145:747-762.

32. Wijeratne AJ, Zhang W, Sun Y, Liu W, Albert R, Zheng Z, Oppenheimer DG, Zhao D, Ma H: Differential gene expression in Arabidopsiswild-type and mutant anthers: insights into anther cell differentiation and regulatory networks. Plant I 2007, 52:14-29.

33. Honys D, Twell D: Comparative analysis of the Arabidopsispollen transcriptome. Plant Physiol 2003, 132:640-652.

34. Hsu YF, Tzeng JD, Liu MC, Yei FL, Chung MC, Wang CS: Identification of anther-specific/predominant genes regulated by gibberellin during development of lily anthers. J Plant Physiol 2008, 165:553-563.

35. Xu J, Yang CY, Yuan Z, Zhang DS, Gondwe MY, Ding ZW, Liang WQ, Zhang DB, Wilson ZA: The aborted microspores regulatory network is required for postmeiotic male reproductive development in Arabidopsisthaliana. Plant Cell 2010, 22:91-107.

36. Hirano K, Aya K, Hobo T, Sakakibara H, Kojima M, Shim RA, Hasegawa Y, Ueguchi-Tanaka M, Matsuoka M: Comprehensive transcriptome analysis of phytohormone biosynthesis and signaling genes in microspore/pollen and tapetum of rice. Plant Cell Physiol 2008, 49:1429-1450.

37. Khandelwal A, Elvitigala T, Ghosh B, Quatrano R: Arabidopsistranscriptome reveals control circuits regulating redox homeostasis and the role of an AP2 transcription factor. Plant Physiol 2008, 148:2050-2058.

38. Mentzen WI, Wurtele ES: Regulon organization of Arabidopsis. BMC Plant Biol 2008, 8:99

39. Aoki K, Ogata Y, Shibata D: Approaches for extracting practical information from gene co-expression networks in plant biology. Plant Cell Physiol 2007, 48:381-390.

40. Li X, Duan X, Jiang H, Sun Y, Tang Y, Yuan Z, Guo J, Liang W, Chen L, Yin J, et al: Genome-wide analysis of basic/helix-loop-helix transcription factor family in rice and Arabidopsis. Plant Physiol 2006, 141:1167-1184.

41. Matus JT, Aquea F, Arce-Johnson P: Analysis of the grape MYB R2R3 subfamily reveals expanded wine quality-related clades and conserved gene structure organization across Vitisand Arabidopsisgenomes. BMC Plant Biol 2008, 8:83.

42. Wu KL, Guo ZJ, Wang HH, Li J: The WRKY family of transcription factors in rice and Arabidopsisand their origins. DNA Res 2005, 12:9-26.

43. Zhang X, Feng B, Zhang Q, Zhang D, Altman N, Ma H: Genome-wide expression profiling and identification of gene activities during early flower development in Arabidopsis. Plant Mol Biol 2005, 58:401-419.

44. Mohrmann R, de Wit H, Verhage M, Neher E, Sorensen JB: Fast vesicle fusion in living cells requires at least three SNARE complexes. Science 2010, 330:502-505

45. Zipfel C: Pattern-recognition receptors in plant innate immunity. Curr Opin Immunol 2008, 20:10-16.

46. Jurgens G, El-Kasmi F, Pacher T, Strompen G, Stierhof YD, Muller LM Koncz C, Mayer U: ArabidopsisSNARE protein SEC22 is essential for gametophyte development and maintenance of Golgi-stack integrity. Plant J 2011, 66:268-279.

47. Sato MH, Nakamura N, Ohsumi Y, Kouchi H, Kondo M, HaraNishimura I, Nishimura M, Wada Y: The AtVAMencodes a syntaxin-related molecule implicated in the vacuolar assembly in Arabidopsisthaliana. J Biol Chem 1997, 272:24530-24535.

48. Chow B, McCourt P: Plant hormone receptors: perception is everything. Genes Dev 2006, 20:1998-2008.

49. Chen J: Characterization of the Arabidopsisthermosensitive mutant atts02reveals an important role for galactolipids in thermotolerance. Plant Cell Environ 2006, 29:1671-1671.

50. Yang KZ, Xia C, Liu XL, Dou XY, Wang W, Chen LQ, Zhang XQ, Xie LF, He L, Ma $X$, et al: A mutation in THERMOSENSITIVE MALE STERILE1, encoding a heat shock protein with DnaJ and PDI domains, leads to thermosensitive gametophytic male sterility in Arabidopsis. Plant J 2009, 57:870-882.

51. Peng J: Gibberellin and jasmonate crosstalk during stamen development. J Integr Plant Biol 2009, 51:1064-1070.

52. Moon J, Parry G, Estelle M: The ubiquitin-proteasome pathway and plant development. Plant Cell 2004, 16:3181-3195.

53. Meng $X$, Sun $P$, Kao TH: S-RNase-based self-incompatibility in Petuniainflata. Ann Bot 2010, 108:637-646.

54. van Wijk SJL, Timmers HTM: The family of ubiquitin-conjugating enzymes (E2s): deciding between life and death of proteins. FASEB J 2010, 24:981-993.

55. Wang XL, Li XB: The GhACS1gene encodes an acyl-CoA synthetase which is essential for normal microsporogenesis in early anther development of cotton. Plant J 2009, 57:473-486. 
56. Surpin M, Raikhel N: Traffic jams affect plant development and signal transduction. Nat Rev Mol Cell Biol 2004, 5:100-109.

57. Carter CJ, Bednarek SY, Raikhel NV: Membrane trafficking in plants: new discoveries and approaches. Curr Opin Plant Biol 2004, 7:701-707.

58. Jurgens G: Membrane trafficking in plants. Annu Rev Cell Dev Biol 2004 20:481-504.

59. Libault M, Wan J, Czechowski T, Udvardi M, Stacey G: Identification of 118 Arabidopsis transcription factor and 30 ubiquitin-ligase genes responding to chitin, a plant-defense elicitor. Mol Plant Microbe Interact 2007, 20:900-911.

60. Ascencio-lbanez JT, Sozzani R, Lee TJ, Chu TM, Wolfinger RD, Cella R, Hanley-Bowdoin L: Global analysis of Arabidopsisgene expression uncovers a complex array of changes impacting pathogen response and cell cycle during geminivirus infection. Plant Physiol 2008, 148:436-454

61. Pien S, Fleury D, Mylne JS, Crevillen P, Inze D, Avramova Z, Dean C, Grossniklaus U: ARABIDOPSIS TRITHORAX1 dynamically regulates flowering locus $C$ activation via histone 3 lysine 4 trimethylation. Plant Cell 2008, 20:580-588.

62. Rubinelli $\mathrm{P}, \mathrm{Hu}$ Y, Ma H: Identification, sequence analysis and expression studies of novel anther-specific genes of Arabidopsisthaliana. Plant Mol Biol 1998, 37:607-619.

63. de Azevedo Souza C, Kim SS, Koch S, Kienow L, Schneider K, McKim SM, Haughn GW, Kombrink E, Douglas CJ: A novel fatty Acyl-CoA Synthetase is required for pollen development and sporopollenin biosynthesis in Arabidopsis. Plant Cell 2009, 21:507-525.

64. Aarts MG, Hodge R, Kalantidis K, Florack D, Wilson ZA, Mulligan BJ, Stiekema WJ, Scott R, Pereira A: The ArabidopsisMALE STERILITY 2 protein shares similarity with reductases in elongation/condensation complexes. Plant J 1997, 12:615-623.

65. Feng X, Dickinson HG: Cell-cell interactions during patterning of the Arabidopsisanther. Biochem Soc Trans 2010, 38:571-576.

66. Toledo-Ortiz G, Huq E, Quail PH: The Arabidopsisbasic/helix-loop-helix transcription factor family. Plant Cell 2003, 15:1749-1770.

67. Bailey PC, Martin C, Toledo-Ortiz G, Quail PH, Huq E, Heim MA, Jakoby M, Werber M, Weisshaar B: Update on the basic helix-loop-helix transcription factor gene family in Arabidopsisthaliana. Plant Cell 2003, 15:2497-2502.

68. Brioudes F, Joly C, Szecsi J, Varaud E, Leroux J, Bellvert F, Bertrand C, Bendahmane M: Jasmonate controls late development stages of petal growth in Arabidopsis thaliana. Plant Journal 2009, 60:1070-1080

69. Szecsi J, Joly C, Bordji K, Varaud E, Cock JM, Dumas C, Bendahmane M: BIGPETALp, a bHLH transcription factor is involved in the control of Arabidopsispetal size. EMBO J 2006, 25:3912-3920.

70. Parenicova L, de Folter S, Kieffer M, Horner DS, Favalli C, Busscher J, Cook HE, Ingram RM, Kater MM, Davies B, et al: Molecular and phylogenetic analyses of the complete MADS-box transcription factor family in Arabidopsis: new openings to the MADS world. Plant Cell 2003, 15:1538-1551

71. Ma H: Regulatory genes in plant development: MADS. Encyclopedia of Life Sciences. 2.0 edition. Chichester: John Wiley \& Sons, Ltd; 2009.

72. Irish VF, Sussex IM: Function of the apetala-1 gene during Arabidopsisfloral development. Plant Cell 1990, 2:741-753.

73. Goto K, Meyerowitz EM: Function and regulation of the Arabidopsisfloral homeotic gene PISTILLAT. Genes Dev 1994, 8:1548-1560.

74. Jack T, Brockman LL, Meyerowitz EM: The homeotic gene APETALAof Arabidopsisthaliana encodes a MADS box and is expressed in petals and stamens. Cell 1992, 68:683-697.

75. Pinyopich A, Ditta GS, Savidge B, Liljegren SJ, Baumann E, Wisman E, Yanofsky MF: Assessing the redundancy of MADS-box genes during carpel and ovule development. Nature 2003, 424:85-88.

76. Favaro R, Pinyopich A, Battaglia R, Kooiker M, Borghi L, Ditta G, Yanofsky MF, Kater MM, Colombo L: MADS-box protein complexes control carpel and ovule development in Arabidopsis. Plant Cell 2003, 15:2603-2611.

77. Werner JD, Borevitz JO, Warthmann N, Trainer GT, Ecker JR, Chory J, Weigel D: Quantitative trait locus mapping and DNA array hybridization identify an FLM deletion as a cause for natural flowering-time variation. Proc Natl Acad Sci USA 2005, 102:2460-2465.

78. Liu C, Chen H, Er HL, Soo HM, Kumar PP, Han JH, Liou YC, Yu H: Direct interaction of AGL24 and SOC1 integrates flowering signals in Arabidopsis. Development 2008, 135:1481-1491.
79. Adamczyk BJ, Lehti-Shiu MD, Fernandez DE: The MADS domain factors AGL15 and AGL18 act redundantly as repressors of the floral transition in Arabidopsis. Plant J 2007, 50:1007-1019.

80. Gu Q, Ferrandiz C, Yanofsky MF, Martienssen R: The FRUITFULMADS-box gene mediates cell differentiation during Arabidopsifruit development. Development 1998, 125:1509-1517.

81. Portereiko MF, Lloyd A, Steffen JG, Punwani JA, Otsuga D, Drews GN: AGL80 is required for central cell and endosperm development in Arabidopsis. Plant Cell 2006, 18:1862-1872.

82. Riechmann JL, Ratcliffe OJ: A genomic perspective on plant transcription factors. Curr Opin Plant Biol 2000, 3:423-434.

83. Aya K, Ueguchi-Tanaka M, Kondo M, Hamada K, Yano K, Nishimura M, Matsuoka M: Gibberellin modulates anther development in rice via the transcriptional regulation of GAMYB. Plant Cell 2009, 21:1453-1472.

84. Millar AA, Gubler F: The ArabidopsisGAMYB-like genes, MYB3and MYB6, are microRNA-regulated genes that redundantly facilitate anther development. Plant Cell 2005, 17:705-721.

85. Zhong R, Richardson EA, Ye ZH: The MYB46 transcription factor is a direct target of SND1 and regulates secondary wall biosynthesis in Arabidopsis. Plant Cell 2007, 19:2776-2792

86. Yang C, Xu Z, Song J, Conner K, Vizcay Barrena G, Wilson ZA: ArabidopsisMYB26/MALE STERILE35 regulates secondary thickening in the endothecium and is essential for anther dehiscence. Plant Cell 2007, 19:534-548.

87. Steiner-Lange S, Unte US, Eckstein L, Yang C, Wilson ZA, Schmelzer E, Dekker K, Saedler H: Disruption of Arabidopsisthaliana MYB26 results in male sterility due to non-dehiscent anthers. Plant J 2003, 34:519-528.

88. Eulgem T, Rushton PJ, Robatzek S, Somssich IE: The WRKY superfamily of plant transcription factors. Trends Plant Sci 2000, 5:199-206.

89. Storey JD, Tibshirani R: Statistical significance for genome-wide studies. Proc Natl Acad Sci USA 2003, 100:9440-9445.

90. Zhou X, Su Z: EasyGO: gene ontology-based annotation and functional enrichment analysis tool for agronomical species. BMC Genomics 2007, 8:246.

91. Zahn LM, Ma X, Altman NS, Zhang Q, Wall PK, Tian D, Gibas CJ, Gharaibeh R, Leebens-Mack JH, Depamphilis CW, et al: Comparative transcriptomics among floral organs of the basal eudicot Eschscholzia californica as reference for floral evolutionary developmental studies. Genome Biol 2010, 11:R101.

92. Livak KJ, Schmittgen TD: Analysis of relative gene expression data using real-time quantitative PCR and the 2(T)(-Delta Delta C) method. Methods 2001, 25:402-408.

doi:10.1186/1471-2229-12-23

Cite this article as: Ma et al.: AMS-dependent and independent

regulation of anther transcriptome and comparison with those affected by other Arabidopsis anther genes. BMC Plant Biology 2012 12:23.

\section{Submit your next manuscript to BioMed Central and take full advantage of:}

- Convenient online submission

- Thorough peer review

- No space constraints or color figure charges

- Immediate publication on acceptance

- Inclusion in PubMed, CAS, Scopus and Google Scholar

- Research which is freely available for redistribution

Submit your manuscript at www.biomedcentral.com/submit
C Biomed Central 